\title{
Canadian Thoracic Society recommendations for management of chronic obstructive pulmonary disease - 2007 update
}

\author{
Denis E O'Donnell MD ${ }^{1}$ Chair*, Shawn Aaron $\mathrm{MD}^{2 *}$, Jean Bourbeau MD ${ }^{3 *}$, Paul Hernandez $\mathrm{MD}^{4 *}$, \\ Darcy D Marciniuk $M D^{5 *}$, Meyer Balter $\mathrm{MD}^{6}$, Gordon Ford $M D^{7}$, Andre Gervais $M D^{8}$, Roger Goldstein $\mathrm{MD}^{6}$, \\ Rick Hodder $\mathrm{MD}^{2}$, Alan Kaplan $\mathrm{MD}^{9}$, Sean Keenan $M D^{10}$, Yves Lacasse $M D^{11}$, Francois Maltais $\mathrm{MD}^{11}$, \\ Jeremy Road $M D^{10}$, Graeme Rocker $M D^{4}$, Don Sin $M D^{10}$, Tasmin Sinuff $M D^{12}$, Nha Voduc $M D^{2}$
}

DE O’Donnell, S Aaron, J Bourbeau, et al. Canadian Thoracic Society recommendations for management of chronic obstructive pulmonary disease - 2007 update. Can Respir J 2007;14(Suppl B):5B-32B.

Chronic obstructive pulmonary disease (COPD) is a major respiratory illness in Canada that is both preventable and treatable. Our understanding of the pathophysiology of this complex condition continues to grow and our ability to offer effective treatment to those who suffer from it has improved considerably. The purpose of the present educational initiative of the Canadian Thoracic Society (CTS) is to provide up to date information on new developments in the field so that patients with this condition will receive optimal care that is firmly based on scientific evidence. Since the previous CTS management recommendations were published in 2003, a wealth of new scientific information has become available. The implications of this new knowledge with respect to optimal clinical care have been carefully considered by the CTS Panel and the conclusions are presented in the current document. Highlights of this update include new epidemiological information on mortality and prevalence of COPD, which charts its emergence as a major health problem for women; a new section on common comorbidities in COPD; an increased emphasis on the meaningful benefits of combined pharmacological and nonpharmacological therapies; and a new discussion on the prevention of acute exacerbations. A revised stratification system for severity of airway obstruction is proposed, together with other suggestions on how best to clinically evaluate individual patients with this complex disease. The results of the largest randomized clinical trial ever undertaken in COPD have recently been published, enabling the Panel to make evidence-based recommendations on the role of modern pharmacotherapy. The Panel hopes that these new practice guidelines, which reflect a rigorous analysis of the recent literature, will assist caregivers in the diagnosis and management of this common condition.

Key Words: Management; National guidelines; Obstructive pulmonary disease
Les recommandations de la Société canadienne de thoracologie au sujet de la prise en charge de la maladie pulmonaire obstructive chronique - Mise à jour de 2007

La maladie pulmonaire obstructive chronique (MPOC) est une maladie respiratoire majeure au Canada, à la fois évitable et traitable. Notre compréhension de la physiopathologie de cette maladie complexe continue d'évoluer, et notre capacité d 'offrir un traitement efficace aux personnes atteintes s'est améliorée considérablement. La présente initiative en matière d'éducation de la Société canadienne de thoracologie (SCT) vise à fournir de l'information à jour au sujet des progrès dans le domaine, afin que les patients atteints de cette maladie reçoivent des soins optimaux fondés sur des données probantes solides. Depuis la publication des dernières recommandations de prise en charge de la SCT en 2003, on a mis au jour une pléthore de nouvelles données scientifiques. Le groupe de travail de la SCT a évalué consciencieusement les conséquences de ces nouvelles connaissances en matière de soins cliniques optimaux, et le présent document contient les conclusions tirées de cet examen. Les faits saillants de cette mise à jour sont de nouvelles données épidémiologiques sur la mortalité et la prévalence de la MPOC, qui en révèlent l'émergence comme trouble de santé d'importance pour les femmes, une nouvelle rubrique sur les comorbidités de la MPOC, une plus grande attention accordée aux bienfaits significatifs de l'association des thérapies pharmacologiques et non pharmacologiques et un nouvel exposé sur la prévention des exacerbations aiguës. On propose un système révisé de stratification pour établir la gravité de l'obstruction des voies aériennes, de même que d'autres suggestions sur le meilleur moyen de procéder à l'évaluation clinique de chaque patient atteint de cette maladie complexe. Les résultats du plus grand essai clinique aléatoire jamais entrepris dans le domaine de la MPOC ont récemment été publiés, ce qui a permis au groupe de travail de présenter des recommandations probantes sur le rôle de la pharmacothérapie moderne. Le groupe de travail espère que ces nouvelles lignes de pratique, qui reflètent une analyse rigoureuse des publications récentes, aideront les dispensateurs de soins dans le diagnostic et la prise en charge de cette maladie courante.

* Member of the editorial committee

${ }^{1}$ Queen's University, Kingston; ${ }^{2}$ University of Ottawa, Ottawa, Ontario; ${ }^{3}$ McGill University, Montreal, Quebec; ${ }^{4}$ Dalhousie University, Halifax, Nova Scotia; ${ }^{5}$ University of Saskatchewan, Saskatoon, Saskatchewan; ${ }^{6}$ University of Toronto, Toronto, Ontario; ${ }^{7}$ University of Alberta, Calgary, Alberta; ${ }^{8}$ University of Montreal, Montreal, Quebec; ${ }^{9}$ Family Physician Airways Group of Canada, Richmond Hill, Ontario;

${ }^{10}$ University of British Columbia, Vancouver, British Columbia; ${ }^{11}$ Université Laval, Sainte-Foy, Québec; ${ }^{12}$ McMaster University, Hamilton, Ontario

Correspondence: Dr Denis E O'Donnell, Division of Respiratory and Critical Care Medicine, Department of Medicine, Queen's University, 102 Stuart Street, Kingston, Ontario K7L 2V6. Telephone 613-548-2339, fax 613-549-1459, e-mail odonnell@post.queensu.ca

For the French translation of this article, please visit www.lung.ca/cts-sct 


\section{THE GUIDELINE DEVELOPMENT PROCESS}

The Canadian Thoracic Society (CTS) Review Panel evaluated all peer-reviewed papers published in the area of chronic obstructive pulmonary disease (COPD) from 2003 to the present. Fifteen content experts undertook responsibility to review their designated topics and each submitted his or her analysis and recommendations to the Panel for discussion during two separate conference meetings. Evidence weighting for each recommendation was assigned based on criteria listed in Table 1 (1). A working document summarizing the scientific review together with consensus recommendations (draft i) was circulated to the Panel for feedback and final approval. The revised draft (ii) was then widely circulated for feedback from external experts from affiliated societies (family physicians, nursing, physical therapy, respiratory therapy, pharmacists). The final draft incorporated revisions from these numerous experts and was submitted for publication.

\section{DEFINITION}

COPD is a respiratory disorder largely caused by smoking, and is characterized by progressive, partially reversible airway obstruction and lung hyperinflation, systemic manifestations, and increasing frequency and severity of exacerbations.

COPD is usually suspected in patients with a significant smoking history who present with progressive exertional dyspnea, cough and/or sputum production, and frequent respiratory tract infections. All patients with suspected COPD should have their lung function assessed by spirometry (2). The forced expiratory volume in $1 \mathrm{~s}$ to forced vital capacity ratio $\left(\mathrm{FEV}_{1} / \mathrm{FVC}\right)$ is the most important measurement for the identification of an obstructive impairment (2). A post bronchodilator $\mathrm{FEV}_{1} / \mathrm{FVC}$ ratio of less than 0.7 defines airflow obstruction that is not fully reversible, and is necessary to establish a diagnosis of COPD.

\section{Mortality}

\section{EPIDEMIOLOGY OF COPD IN CANADA}

In 2004, COPD was the fourth leading cause of death in both men and women in Canada (3), a significant increase from 1999 when it was the fifth leading cause of death (4). In 2004, 5152 men and 4455 women died of COPD, a mortality increase of more than $12 \%$ in women from $1999(3,4)$. The number of COPD deaths in women increased by $117 \%$ from 1988 to 2003 and will likely surpass the number of deaths in men in the near future $(3,4)$ (Figure 1). The number of deaths among men decreased by 7\% within this time frame, although it still remains high. Age-standardized mortality rates increase sharply for those over 75 years of age. The change in age composition of the population with an increasing number of people older than 65 years of age will result in continued increases in mortality rates for COPD (particularly in women) in the foreseeable future. Furthermore, the estimated mortality rate is a significant underestimation because the primary cause of death is often coded as another diagnosis, such as congestive heart failure or pneumonia (5).

\section{Prevalence}

Currently available prevalence estimates based on selfreporting or physician diagnosis likely significantly underestimate the true prevalence of COPD $(6,7)$. According to the 2005 Canadian Community Health Survey, 4.4\% of
TABLE 1

\section{Levels of evidence*}

Level of evidence

1. Evidence from one or more randomized trials or meta-analyses

2. Evidence from one or more well-designed cohort or case-control studies

3. Consensus from expert groups based on clinical experience

Evidence was further subdivided into a number of categories

A. Good evidence to support a recommendation for use

B. Moderate evidence to support a recommendation for use

C. Poor evidence to support a recommendation for or against use

D. Moderate evidence to support a recommendation against use

E. Good evidence to support a recommendation against use

*Schema used previously by the Canadian Thoracic Society for guidelines development (1).

Canadians aged 35 years or older (over 700,000 adults) have probable COPD based on self-reporting of diagnoses made by health care professionals (4). For the same age group, the prevalence among men is $3.9 \%$ and the prevalence for women now stands at $4.8 \%$. The overall prevalence of probable COPD has been similar since 1994/1995, although the questions used to elicit the information have differed somewhat over the years. In 2000/2001, the prevalence of probable COPD increased with age for both men and women (Figure 2). Women have a higher prevalence of COPD in all age groups except for the 75 year and older age group, in which the male prevalence is higher (men $11.8 \%$, women $7.5 \%)$.

\section{RISK FACTORS}

In Canada, cigarette smoke is the main inflammatory trigger in COPD. COPD develops in some smokers but not others due to a complex interaction between the susceptible host and its changing environment. Some host factors have been well studied, including alpha ${ }_{1}$-antitrypsin (AAT) deficiency, a history of childhood viral infections and bronchial hyper-responsiveness. Environmental risk factors other than exposure to tobacco smoke include occupational exposures and air pollution $(3,8,9)$.

\section{PATHOPHYSIOLOGY OF COPD}

COPD is characterized by complex and diverse pathophysiological manifestations. Persistent inflammation of the small and large airways, as well as the lung parenchyma and its vasculature, occurs in a highly variable combination that differs from patient to patient.

Understanding of this inflammatory process continues to grow (10-22). Evidence of airway inflammation is present even in early disease where spirometric abnormalities are minor (23). The inflammatory process in COPD persists long after the inciting stimulus (cigarette smoke) is withdrawn (22). It is clear that the inflammatory process in COPD is different in many important respects from that in asthma $(18,24)$.

\section{Expiratory flow limitation}

Expiratory flow limitation is the pathophysiological hallmark of COPD. This arises because of intrinsic airway factors that increase resistance (eg, mucosal inflammation and edema, airway remodelling and fibrosis, and secretions) and extrinsic airway factors (eg, reduced airway tethering from emphysema and regional extraluminal compression by adjacent overinflated alveolar units) $(19,20,23)$. Emphysematous destruction also 


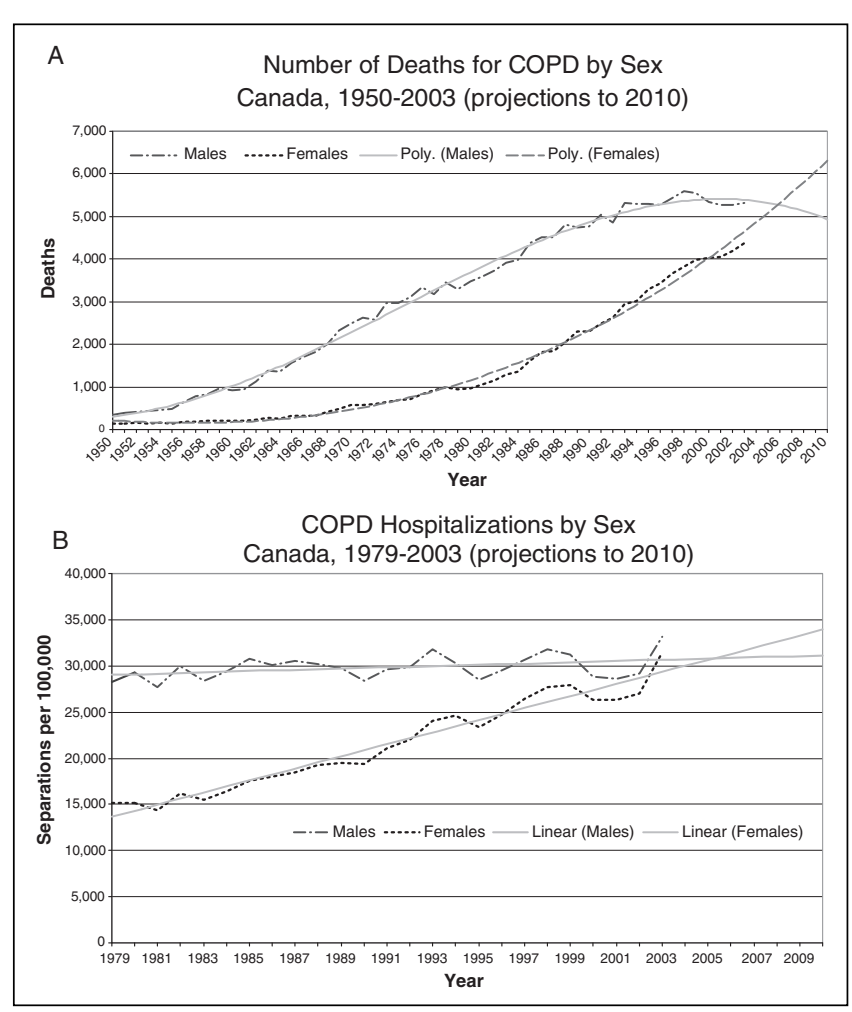

Figure 1) Number of chronic obstructive pulmonary disease (COPD) deaths (A) and hospitalizations (B), actual and projected, in Canada. International Classification of Diseases, 10th Edition (ICD10) codes: J40-J44. Note that the coding schemes for this condition changed in 1968, 1978 and 2000 and this may influence trends. Standardized rate uses 1991 Canadian population. Prior to 1993, includes only the 10 Canadian provinces. Source: Centre for Chronic Disease Prevention and Control, Public Health Agency of Canada, 2006, using Statistics Canada, Vital Statistics Data

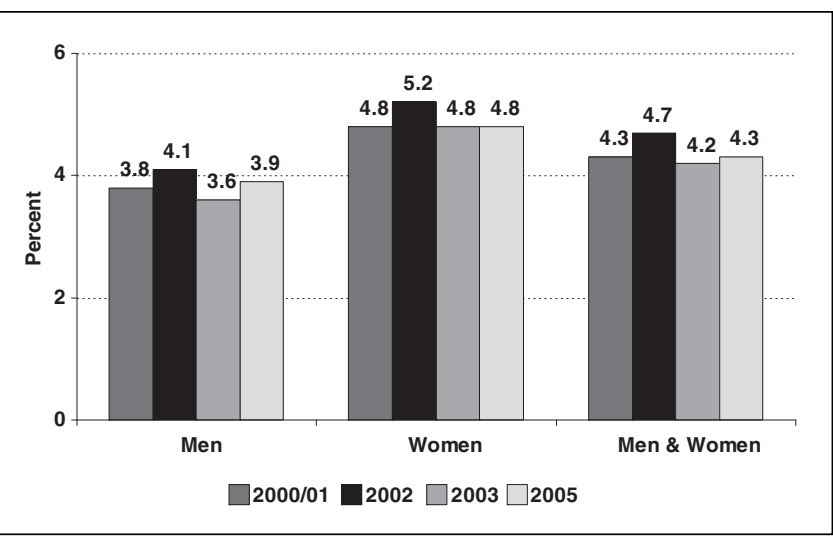

Figure 2) Prevalence of physician-diagnosed chronic obstructive pulmonary disease in Canadian adults 35 years of age and over, by sex, in 2000/01, 2002, 2003 and 2005. Source: Centre for Chronic Disease Prevention and Control, Public Health Agency of Canada, using data from Canadian Community Health Survey (share file), Statistics Canada, 2006

reduces elastic lung recoil and, thus, the driving pressure for expiratory flow, further compounding flow limitation. Further modulation of airway calibre in COPD is provided by the

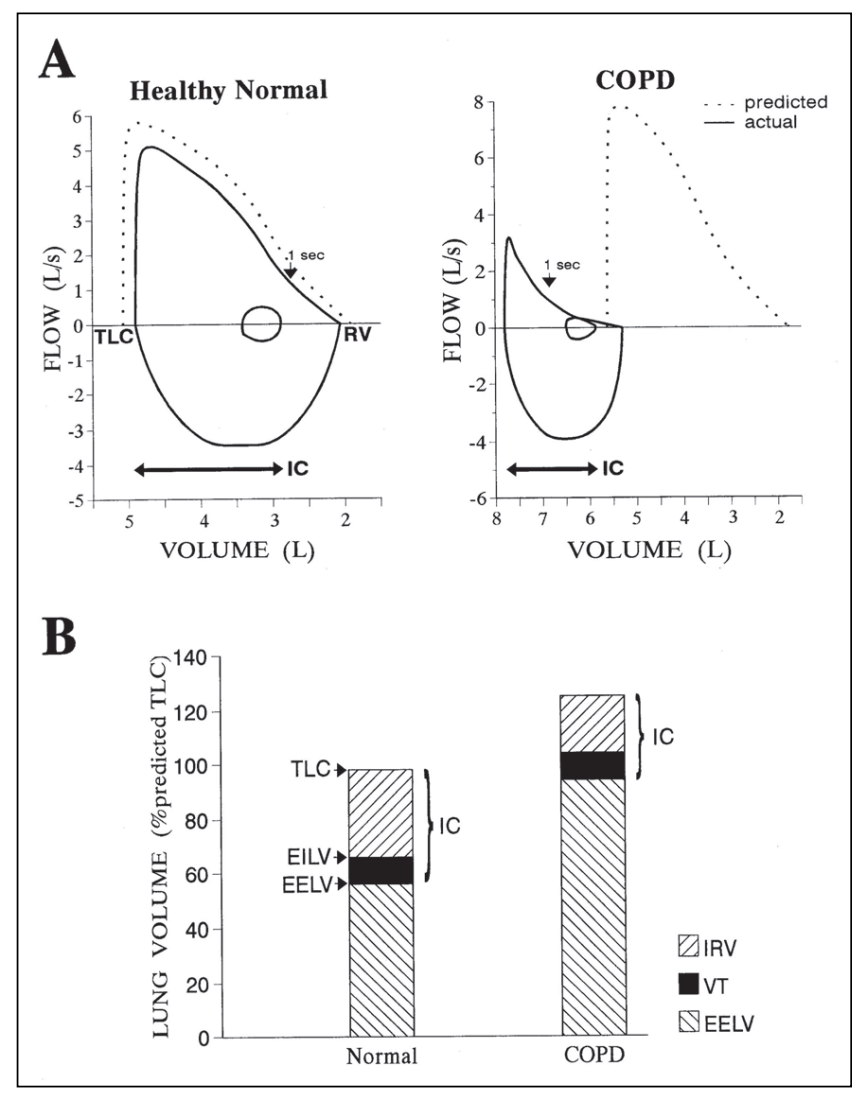

Figure 3) Resting maximal flow-volume loops (spirometry) (A) and lung volumes (B) in a typical patient with chronic obstructive pulmonary disease (COPD). EELV End-expiratory lung volume; EILV End-inspiratory lung volume; IC Inspiratory capacity; IRV Inspiratory reserve volume; RV Residual volume; TLC Total lung capacity; VT Tidal volume

autonomic nervous system, which can be pharmacologically manipulated.

\section{Lung hyperinflation}

Expiratory flow limitation with dynamic collapse of the small airways compromises the ability of patients to expel air during forced and quiet expiration; thus, air trapping and lung overinflation occurs (Figure 3). The volume of air in the lungs at the end of quiet expiration (ie, end-expiratory lung volume) is increased and is a continuous dynamic variable in COPD. When the breathing rate acutely increases (and expiratory time diminishes) as, for example, during exercise in COPD, there is further dynamic lung overinflation as a result of air trapping, which contributes to dyspnea (25). Acute-on-chronic hyperinflation has been shown to be an important determinant of shortness of breath during exercise and with exacerbations in COPD (25-29).

\section{Respiratory complications}

Respiratory failure: Oxygen uptake and carbon dioxide elimination by the lungs are compromised because of regional inequalities of ventilation and perfusion throughout the lungs, leading ultimately to hypoxemia and hypercapnia.

Pulmonary hypertension: Destruction of the vascular bed due to emphysema, together with the vasoconstrictor effects of chronic hypoxia, lead to pulmonary hypertension and right 
heart failure (30). New evidence suggests that pulmonary hypertension is due to direct toxic effects of tobacco smoke on the pulmonary vasculature, resulting in the production of endothelial-derived vasoactive mediators and vascular remodelling. Changes seen are similar to those found in idiopathic pulmonary arterial hypertension $(31,32)$. The presence of pulmonary hypertension in COPD indicates a poor prognosis $(33,34)$. Significant pulmonary hypertension at rest is rarely a problem in COPD and it affects only a minority of patients. When severe pulmonary hypertension occurs in less advanced COPD, the presence of another disease should be considered (35).

\section{COMORBIDITY IN COPD}

In the recent Towards a Revolution in COPD Health (TORCH) trial (36), which followed more than 6000 patients with COPD over a three-year period, $35 \%$ of deaths were adjudicated to be due to pulmonary causes, $27 \%$ to cardiovascular disease, $21 \%$ to cancer and in $7 \%$ the primary cause of death was not known. Comorbidity has been defined as a recognized and distinct disease entity coexisting with the primary disease of interest. COPD is associated with many comorbid conditions, particularly those related to the cardiovascular system. Other comorbidities frequently associated with COPD include osteopenia and osteoporosis (37), glaucoma and cataracts (38), cachexia and malnutrition (39), peripheral muscle dysfunction (40), cancer (41) and the metabolic syndrome (42). Rates of recognized depression in COPD vary from $20 \%$ to $50 \%$ and increase with disease severity $(43,44)$.

Soriano et al (38) found that compared with controls, COPD patients had increased risk of angina (a 1.67-fold increase) and myocardial infarction (a 1.75-fold increase). They also had increased risk for fractures (a 1.58-fold increase) and glaucoma (a 1.29-fold increase). Sidney et al (45) found that compared with age- and sex-matched control subjects, COPD patients were 2.7 times more likely be hospitalized for ventricular arrhythmias, 2.1 times more likely to be hospitalized for atrial fibrillation, two times more likely to be hospitalized for angina, 1.9 times more likely to be hospitalized for myocardial infarction and 3.9 times more likely to be hospitalized for congestive heart failure. Overall, COPD patients were 1.8 times more likely to die from cardiovascular causes of mortality and two times more likely to be hospitalized for cardiovascular diseases than were age- and sex-matched control subjects (45).

The main causes of mortality in mild or moderate COPD are lung cancer and cardiovascular diseases, while in more advanced COPD (less than $60 \% \mathrm{FEV}_{1}$ ), respiratory failure becomes the predominant cause. However, even in patients with advanced COPD, cardiovascular events account for approximately $20 \%$ of all deaths (42). Cardiovascular disease also leads to hospitalization of COPD patients. For example, in the Lung Health Study (46), cardiovascular causes accounted for $42 \%$ of first hospitalizations and $44 \%$ of second hospitalizations of patients with relatively mild COPD. In comparison, respiratory causes accounted for only $14 \%$ of hospitalizations.

Not only do comorbidities increase the risk of certain causes of mortality, they also increase all-cause mortality risk in COPD. Antonelli Incalzi et al (47) found that five-year mortality risk was significantly predicted by an $\mathrm{FEV}_{1}$ less than $0.59 \mathrm{~L}$ (hazard ratio $[\mathrm{HR}]=1.49)$ and age $(\mathrm{HR}=1.04)$, as well as electrocardiogram signs of right ventricular hypertrophy $(\mathrm{HR}=1.76)$, chronic renal failure $(\mathrm{HR}=1.79)$, and myocardial infarction or ischemia $(\mathrm{HR}=1.42)$, with an overall sensitivity of $63 \%$ and a specificity of $77 \%$.

Skeletal muscle dysfunction is also a significant comorbidity. In more advanced COPD, when patients become immobilized with dyspnea, there are measurable metabolic and structural abnormalities of peripheral locomotor muscles. The prevalence of peripheral muscle wasting is estimated at $30 \%$ and increases with disease severity (48). These peripheral muscle abnormalities contribute to exercise intolerance (49), and result from the combined effects of immobility, altered nutritional status, prolonged hypoxia and, possibly, sustained systemic inflammation $(50,51)$. Loss of muscle mass is a predictor of mortality, independent of lung function $(52,53)$.

The mechanistic link between COPD and comorbidities is uncertain. COPD and many of the comorbidities share a common risk factor, namely, cigarette smoking. Recently, some evidence has implicated systemic and pulmonary inflammation as the common link between COPD and certain comorbid conditions, such as lung cancer, cardiovascular disease and cachexia (54-61).

\section{CLINICAL ASSESSMENT}

\section{The importance of prompt diagnosis}

Underdiagnosis of COPD remains a significant problem and many patients already have advanced pulmonary impairment at the time of diagnosis (62). Early diagnosis, when coupled with successful smoking cessation interventions, will provide substantial long-term health benefits (63). Smoking cessation in patients with mild COPD has been shown to slow the progression of decline in $\mathrm{FEV}_{1}$ and, thus, alter the natural history of the disease $(63,64)$. Earlier diagnosis and management may also be important given the availability of effective modern pharmacotherapy, which improves symptoms and health status in patients with COPD. In a recent study (65), approximately 50\% of individuals diagnosed with COPD through screening received new treatment as a result of the diagnosis.

Mass screening of asymptomatic individuals for COPD is not supported by the current evidence and therefore is not recommended. Targeted spirometric testing to establish early diagnosis in individuals at risk for COPD is recommended (8,9,66-69). A postbronchodilator $\mathrm{FEV}_{1} / \mathrm{FVC}$ ratio less than 0.7 confirms the presence of airway obstruction that is not fully reversible and is currently widely accepted as the diagnostic criterion for COPD. However, this fixed ratio can lead to false positive diagnosis in the elderly (70). Comparison of the $\mathrm{FEV}_{1} / \mathrm{FVC}$ ratio to the lower limits of normal adjusted for age and height (ie, below the 5 th percentile of predicted normal) may be preferable (71). If the diagnosis is uncertain, referral to a specialist for further assessment is appropriate.

No clinical, evidence-based criteria currently exist to help guide the caregiver in selecting individuals who are at risk for COPD for diagnostic spirometry. The Canadian Lung Assocation has suggested that patients who are older than 40 years of age and who are current or ex-smokers should undertake spirometry if they answer yes to any one of the following questions:

1. Do you cough regularly?

2. Do you cough up phlegm regularly?

3. Do even simple chores make you short of breath?

4. Do you wheeze when you exert yourself, or at night? 
5. Do you get frequent colds that persist longer than those of other people you know?

Acute exacerbation is a common initial clinical presentation of COPD. Therefore, it is recommended that long-term smokers (current or past) who seek medical attention for treatment of respiratory tract infection should be offered elective diagnostic spirometry when the acute symptoms subside and the patient's condition has stabilized.

Objective indices of airway obstruction often fluctuate over time but must persist and not fully normalize if a diagnosis of COPD is to be made. Accordingly, it is possible that the diagnosis of COPD cannot be established at the first evaluation.

\section{Recommendations}

- Evidence does not support population screening using office spirometry to detect COPD (level of evidence: $2 \mathrm{C}$ ).

- Targeted testing of symptomatic individuals at risk for the development of COPD combined with intensive smoking cessation counselling can slow the progression of disease (level of evidence: 1A).

\section{Clinical evaluation of the COPD patient}

History: Clinical assessment begins with a thorough history which should include the following:

1. Quantification of tobacco consumption: total pack years $=($ number of cigarettes smoked per day $\div 20) \times$ number of years of smoking. Occupational or environmental exposures to other lung irritants should also be recorded.

2. Assessment of the severity of breathlessness using the Medical Research Council (MRC) dyspnea scale (72) (Table 2). MRC ratings provide prognostic information on survival in COPD (73).

3. Assessment of the frequency and severity of exacerbations.

4. Assessment of symptoms that could point to complications of COPD, such as ankle swelling that might indicate cor pulmonale. A history of progressive weight loss (with reduced fat-free mass) indicates a poor prognosis in COPD (53).

5. Assessment of symptoms that suggest comorbidities (eg, heart and circulatory diseases, lung cancer, osteoporosis, musculoskeletal disorders, anxiety and depression).

\section{Assessment of current medical treatment.}

Physical examination: Physical examination of patients with COPD, although important, is not usually diagnostic and even careful physical examination can underestimate the presence of significant airflow limitation. With more advanced disease, signs of lung hyperinflation, right heart failure and generalized muscle wasting may be evident (74). Physical examination should be undertaken to assess for possible comorbidities.

Investigations: Postbronchodilator spirometry is required to assist in the evaluation of the severity of airway obstruction to establish the diagnosis of COPD.

Additional pulmonary function tests: More extensive pulmonary function testing may be undertaken in selected patients for a more complete clinical characterization of the

\section{TABLE 2}

The Medical Research Council dyspnea scale

\begin{tabular}{|c|c|}
\hline Grade & Description \\
\hline 1 & Not troubled by breathlessness except with strenuous exercise \\
\hline 2 & $\begin{array}{l}\text { Troubled by shortness of breath when hurrying on the level or } \\
\text { walking up a slight hill }\end{array}$ \\
\hline 3 & $\begin{array}{l}\text { Walks slower than people of the same age on the level because of } \\
\text { breathlessness or has to stop for breath when walking at own } \\
\text { pace on the level }\end{array}$ \\
\hline 4 & $\begin{array}{l}\text { Stops for breath after walking about } 100 \text { yards }(90 \mathrm{~m}) \\
\text { or after a few minutes on the level }\end{array}$ \\
\hline 5 & $\begin{array}{l}\text { Too breathless to leave the house or breathless when dressing } \\
\text { or undressing }\end{array}$ \\
\hline
\end{tabular}

Reproduced from reference 72

COPD phenotype. These additional tests may include other tests of airway function (small airway function), inspiratory capacity, static lung volumes, diffusing capacity and tests of respiratory muscle function.

Exercise tests: The 6 minute walking test is a useful test of functional disability and provides prognostic information $(75,76)$. Arterial oxygen desaturation during walking can be measured accurately with a pulse oximeter. Cardiopulmonary exercise testing (77) provides excellent objective measurement of pulmonary impairment, and the peak symptom-limited oxygen uptake during incremental cycle exercise is an independent prognostic factor in COPD (78). Cardiopulmonary exercise testing also has an established role in presurgical evaluation, particularly in patients with more advanced disease. Constant work rate cycle endurance tests can be used to evaluate the impact of therapeutic interventions $(79,80)$.

Blood tests: Arterial blood gas measurements should be considered for patients with an $\mathrm{FEV}_{1}$ less than $40 \%$ predicted if they have low arterial oxygen saturation (less than $92 \%$ on oximetry) (81), or for patients in whom respiratory failure is suspected (77). Venous blood tests may be obtained to assess polycythemia, anemia, AAT level and protease inhibitor type (77). Nutrition and skeletal muscle function: Assessment of nutritional status (eg, body mass index, lean body mass) and peripheral muscle function (eg, strength and endurance testing, dual energy $\mathrm{x}$-ray absorptiometry scans and computed tomography imaging) can be undertaken in selected patients.

Radiology: Chest $\mathrm{x}$-rays are not diagnostic for COPD, but are often required to rule out comorbidities. High-resolution computed tomography scanning can be used to identify the extent and distribution of the airspace dilation that characterizes emphysema, but is currently not routinely required (77).

Echocardiography: Echocardiography, including echo-Doppler estimation of peak right ventricular systolic pressure, can be used to assess pulmonary hypertension in selected patients (77).

Sputum cytology: Although the validation of airflow limitation is best made by spirometry, the validation of airway inflammation may be made by quantitative cell counts in induced or spontaneously expectorated sputum, because bronchitis is an important component of the characteristics of airway disease and difficult to recognize without measurement (82). Sputum differential cell counts may be useful in deciding if inhaled corticosteroids (ICSs) are needed, or to detect an infection that may require treatment with an antibiotic $(83,84)$. Currently, 
TABLE 3

Canadian Thoracic Society chronic obstructive pulmonary disease (COPD) classification of severity by symptoms and disability*, and impairment of lung function

\begin{tabular}{|c|c|}
\hline \multicolumn{2}{|c|}{ Classification by symptoms and disability } \\
\hline COPD stage & Symptoms \\
\hline Mild & $\begin{array}{l}\text { Shortness of breath from } \mathrm{COPD}^{\dagger} \text { when hurrying on the level } \\
\text { or walking up a slight hill (MRC 2) }\end{array}$ \\
\hline Moderate & $\begin{array}{l}\text { Shortness of breath from } \mathrm{COPD}^{\dagger} \text { causing the patient to stop } \\
\text { after walking approximately } 100 \mathrm{~m} \text { (or after a few minutes) } \\
\text { on the level (MRC } 3 \text { to } 4 \text { ) }\end{array}$ \\
\hline Severe & $\begin{array}{l}\text { Shortness of breath from COPD }{ }^{\dagger} \text { resulting in the patient } \\
\text { being too breathless to leave the house, breathless } \\
\text { when dressing or undressing (MRC 5), or the presence of } \\
\text { chronic respiratory failure or clinical signs of right heart } \\
\text { failure }\end{array}$ \\
\hline \multicolumn{2}{|c|}{ Classification by impairment of lung function } \\
\hline COPD stage & Spirometry (postbronchodilator) \\
\hline Mild & $\mathrm{FEV}_{1} \geq 80 \%$ predicted, $\mathrm{FEV}_{1} / \mathrm{FVC}<0.7$ \\
\hline Moderate & $50 \% \leq \mathrm{FEV}_{1}<80 \%$ predicted, $\mathrm{FEV}_{1} / \mathrm{FVC}<0.7$ \\
\hline Severe & $30 \% \leq \mathrm{FEV}_{1}<50 \%$ predicted, $\mathrm{FEV}_{1} / \mathrm{FVC}<0.7$ \\
\hline Very severe & $\mathrm{FEV}_{1}<30 \%$ predicted, $\mathrm{FEV}_{1} / \mathrm{FVC}<0.7$ \\
\hline
\end{tabular}

*Postbronchodilator forced expiratory volume in $1 \mathrm{~s}\left(F E V_{1}\right)$ to forced vital capacity (FVC) ratio less than 0.7 is required for the diagnosis of COPD to be established; + In the presence of non-COPD conditions that may cause shortness of breath (eg, cardiac dysfunction, anemia, muscle weakness, metabolic disorders), symptoms may not appropriately reflect COPD disease severity. Classification of COPD severity should be undertaken with care in patients with comorbid diseases or other possible contributors to shortness of breath. MRC Medical Research Council dyspnea scale

there is no evidence to identify whether the detection of steroid-responsive eosinophilic bronchitis in COPD or asthma indicates the need for long-term corticosteroids. However, a treatment strategy that uses sputum cell counts to guide therapy decreases exacerbations in patients with COPD (85).

Biomarkers: Biomarkers such as C-reactive protein and sputum cytology are being used to investigate the underlying cellular and molecular pathophysiology of COPD. They may be useful in predicting disease progression, disease instability, response to therapy (new and current) and mortality $(41,86,87)$. Genetic factors are known to influence susceptibility to the development of COPD. There is an increasing body of literature supporting the measurement of candidate genes and markers but to date no clinically useful screening gene or marker has been developed to identify susceptible smokers (88-90).

Additional investigations to identify comorbidities are often required in patients with more advanced COPD (see above).

\section{Patient follow-up}

No consensus exists as to which parameters should be routinely used in charting the course of the disease in individual patients. Traditionally, the rate of decline of $\mathrm{FEV}_{1}$ has been used to assess disease progression. Faster rates of decline often occur in active smokers (64) and appear to be greater in patients with frequent exacerbations (91). Other important outcomes which provide prognostic information include the number and severity of exacerbations and hospitalizations (92-97), age (78,98-101), nutritional status (body
TABLE 4

Clinical differences between asthma and chronic obstructive pulmonary disease (COPD)

\begin{tabular}{lll}
\hline & \multicolumn{1}{c}{ Asthma } & \multicolumn{1}{c}{ COPD } \\
\hline Age of onset & Usually $<40$ years & Usually $>40$ years \\
Smoking history & Not causal & Usually $>10$ pack-years \\
Sputum production & Infrequent & Often \\
Allergies & Often & Infrequent \\
Disease course & Stable (with & Progressive worsening \\
& exacerbations) & (with exacerbations) \\
Spirometry & Often normalizes & May improve but never \\
& & normalizes \\
Clinical symptoms & Intermittent and variable & Persistent \\
\hline
\end{tabular}

weight [52], fat-free mass [53], body mass index $[53,78,99,102])$, the presence of gas exchange abnormalities (diffusing capacity $[78,101,103]$, arterial blood gases $[99,100,103]$, use of long-term oxygen therapy [104]), MRC dyspnea scale $(73,78,105)$, the ratio of inspiratory capacity to total lung capacity (105), exercise tolerance (6 minute walking distance $[75,105]$, peak oxygen uptake [78], maximal work rate [98]), use of oral corticosteroids $(100,101)$, the presence of comorbidities $(42,47)$ and the presence of pulmonary hypertension $(33,34)$.

\section{Stratifying disease severity in COPD}

Most existing paradigms for the stratification of disease severity use the $\mathrm{FEV}_{1}(106,107)$. However, there is a relatively poor correlation between the $\mathrm{FEV}_{1}$ and the risk of mortality, and there is no consensus as to which risk stratification system should be used. Some patients with relatively minor abnormalities in spirometry may have significant exertional symptoms and require further investigation. The ideal system would use a composite index with evaluation in the domains of impairment (function), disability (activity) and handicap (participation). The BODE index (body mass index, airflow obstruction, dyspnea and exercise capacity) is a recently published comprehensive grading system of disease severity that better predicts survival than $\mathrm{FEV}_{1}$ alone (108). $\mathrm{FEV}_{1}$ measurement by itself, while necessary for diagnostic purposes and for follow-up of the disease, correlates less well with symptom intensity, exercise capacity and quality of life $(26,109)$. The MRC dyspnea scale represents an easy and useful clinical measure which better reflects overall disease impact among COPD patients (Table 3).

\section{Recommendation}

- Spirometry is required for diagnosis and is useful in assessing severity of airway obstruction. However, after having established a spirometric diagnosis, management decisions should be individualized and guided by the severity of symptoms and disability, as measured by the MRC scale (level of evidence: 3A).

A simple stratification system of severity based on both spirometry and the MRC dyspnea grade is provided in Table 3, with the recognition that measures of impairment and subjective symptoms may be poorly correlated in individual patients. This stratification system requires formal validation but nonetheless provides important clinical information to guide treatment decisions. 


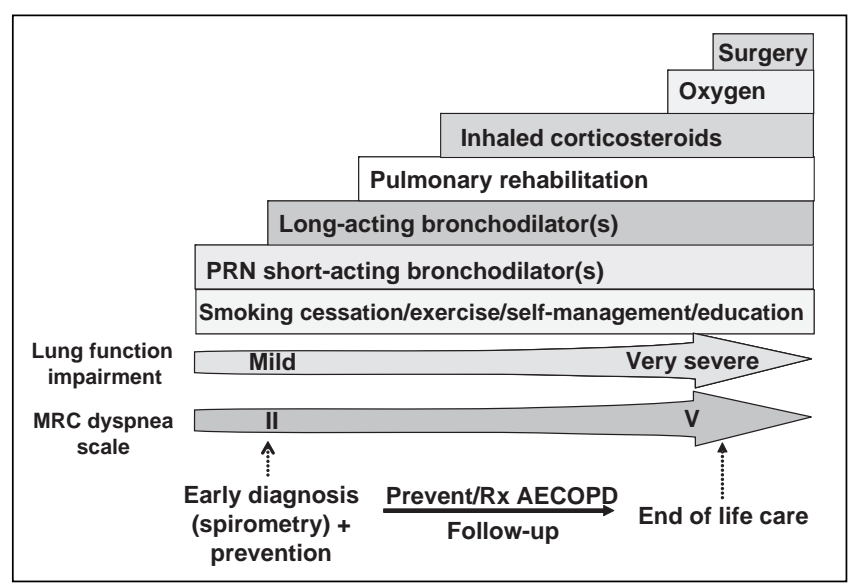

Figure 4) A comprehensive approach to the management of chronic obstructive pulmonary disease (COPD). AECOPD Acute exacerbation of COPD; MRC Medical Research Council; PRN As needed; Rx Treatment

\section{Differential diagnosis of COPD}

COPD versus asthma: In most instances, physicians can readily differentiate between COPD and asthma (Table 4). However, in a small proportion of patients, diagnostic differentiation can be challenging and may require additional investigation. COPD patients generally have a later age of onset of symptoms and have a significant smoking history. In COPD, symptoms are chronic and slowly progressive over years, whereas in asthma, symptoms of shortness of breath are more intermittent and less likely to be associated with progressive disability. When patients exhibit the clinical features outlined above, together with a demonstration of persistent airway obstruction (ie, postbronchodilator $\mathrm{FEV}_{1} / \mathrm{FVC}$ ratio less than 0.7) in response to a trial of acute bronchodilator therapy, this strongly suggests the diagnosis of COPD. Importantly, it should be stressed that a significant bronchodilator response does not exclude the diagnosis of COPD.

Combined COPD and asthma: It is important to identify patients with mixed asthma and COPD (eg, asthmatic patients with a significant smoking history). In practice, the relative contribution of each disease to airway obstruction is often difficult to ascertain. Patients with a large improvement in $\mathrm{FEV}_{1}$ (eg, greater than $0.4 \mathrm{~L}$ ) following an inhaled short-acting bronchodilator likely have underlying asthma (110). Marked diurnal variability of peak expiratory flow rates or significant fluctuations over time in any measure of airway obstruction is also suggestive of asthma. Large spirometric improvements following treatment with inhaled or oral steroids also suggest asthma. Only the baseline eosinophil count in induced sputum has been shown to significantly correlate with reversibility of airway obstruction following treatment with oral corticosteroids (level of evidence: 3B) (111-113). The potential utility of this test in clinical practice needs further assessment. Patients with combined asthma and COPD may benefit from combination therapy with both beta $_{2}$-agonist and anticholinergic bronchodilators, and if the asthma component is prominent, earlier introduction of ICS may be justified. Moreover, education and self-management plans for mixed disease need to be individualized, and will reflect different goals and treatment expectations than for patients with either disease alone.

\section{TABLE 5 \\ Management of symptomatic milder chronic obstructive pulmonary disease*}

Education and smoking cessation programs

Prevention of exacerbations (vaccinations)

Initiation of bronchodilator therapy

Encouragement of regular physical activity

Close follow-up and disease monitoring

*Medical Research Council dyspnea scale grade 2 and/or postbronchodilator forced expiratory volume in $1 \mathrm{~s}\left(F E V_{1}\right)$ to forced vital capacity ratio $<0.70$. $\mathrm{FEV}_{1} \geq 80 \%$ predicted

COPD - differential diagnosis of chronic breathlessness: Other conditions included in the differential diagnosis of older patients presenting with progressive breathlessness include cardiovascular conditions, pulmonary vascular disease (eg, pulmonary emboli), severe deconditioning, obesity, anemia, interstitial lung disease and, rarely, neuromuscular disease. Patients with advanced COPD often have several comorbidities (see above).

When to refer to a specialist

Referral to a specialist may be appropriate when there is uncertainty over the diagnosis; symptoms are severe or disproportionate to the level of obstruction; there is an accelerated decline of function $\left(\mathrm{FEV}_{1}\right.$ decline of $80 \mathrm{~mL}$ or more per year over a two-year period); and the onset of symptoms occurs at a young age. Specialists can also assist in the assessment and management of patients who fail to respond to bronchodilator therapy, or those who require pulmonary rehabilitation or an assessment for oxygen therapy. Specialist assistance may also be needed for the management of patients with severe or recurrent exacerbations of COPD, for patients with complex comorbidities, and for those requiring assessment for surgical intervention (ie, bullectomy, lung volume reduction surgery [LVRS], lung transplantation).

\section{MANAGEMENT OF COPD}

The goals of management of COPD are as follows:

1. Prevent disease progression (smoking cessation);

2. Reduce the frequency and severity of exacerbations;

3. Alleviate breathlessness and other respiratory symptoms;

4. Improve exercise tolerance and daily activity;

5. Treat exacerbations and complications of the disease;

6. Improve health status; and

7. Reduce mortality.

Therapy would be expected to escalate from MRC grade 2 through to grade 5. Patients with an MRC grade of 3 to 5 are disabled and require a more intensive comprehensive management strategy to optimize outcomes, including combined pharmacotherapeutic and nonpharmacological interventions from the outset (Figure 4). A management approach for patients with symptomatically milder COPD (MRC dyspnea score of 2) is outlined in Table 5 .

\section{EDUCATION}

Components of COPD education should be individualized because they will vary with disease severity. Important 


\section{TABLE 6}

Components of a chronic obstructive pulmonary disease (COPD) patient education program

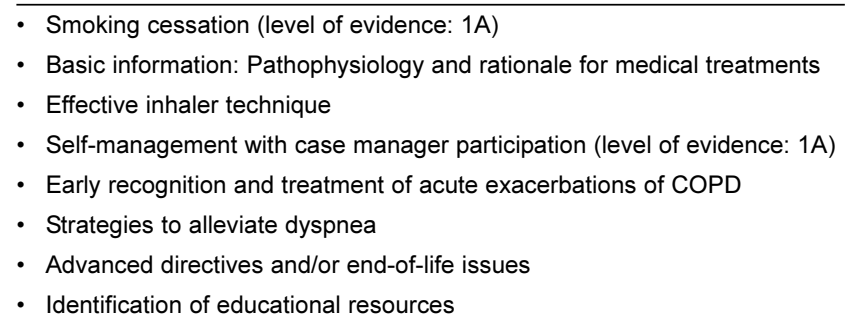

educational components are outlined in Table 6. Education alone is not associated with improved lung function or exercise performance (114). Specific educational interventions, such as self-management programs with the support of a case manager and smoking cessation, have been shown to be effective in reducing health resource utilization, both related and unrelated to management of acute exacerbations of COPD (AECOPD) $(63,115)$.

\section{Recommendation}

- Educational intervention of the patient and the family with supervision and support based on disease-specific self-management principles is valuable, and should be part of the continuum of optimal COPD management in Canada (level of evidence: $1 \mathrm{~A}$ ).

\section{SMOKING CESSATION}

In 2005, 22\% of Canadians aged 12 years and older still smoked, with the highest percentage of smokers (ie, 28\%) in the 20- to 34-year-old cohort (116) (Figure 5). The relationship between smoking status and the development of clinically significant COPD is complex and depends on age, sex and the spirometric definition used for COPD (117). Like the Global Initiative for Chronic Obstructive Lung Disease, the CTS requires an $\mathrm{FEV}_{1} / \mathrm{FVC}$ ratio less than 0.70 to support the diagnosis of COPD; using that criterion, it has been shown that $25 \%$ of current smokers older than 45 years have COPD (117). In this same observational study, the prevalence of COPD in male and female smokers aged 61 to 62 years was 39\% and $46 \%$, respectively. Many other smokers will have objective evidence of damage to smaller airways. Quitting smoking produces only a small improvement of the $\mathrm{FEV}_{1}$. However, the subsequent rate may return toward that of a nonsmoker, thus helping to delay the onset of disability due to COPD. Smoking cessation is the single most effective intervention to reduce the risk of developing COPD and to slow its progression (level of evidence: 1A). Quitting will result in symptomatic relief of chronic cough, sputum expectoration, shortness of breath and wheezing, and reduce the risk of cardiovascular disease and cancer of the lung and other organs. Although approximately $41 \%$ of smokers try to quit smoking each year, only approximately $10 \%$ achieve and maintain abstinence (118).

At least $70 \%$ of smokers visit a physician each year and smoking cessation advice is quoted as an important motivator to quit (119). Quitting advice given to all smokers, regardless of whether they have chronic disease, by physicians (level of evidence: 1A), nonphysician health professionals (level of evidence: 2A), and individual and group counselling (levels of evidence: 1A), increases cessation (119).

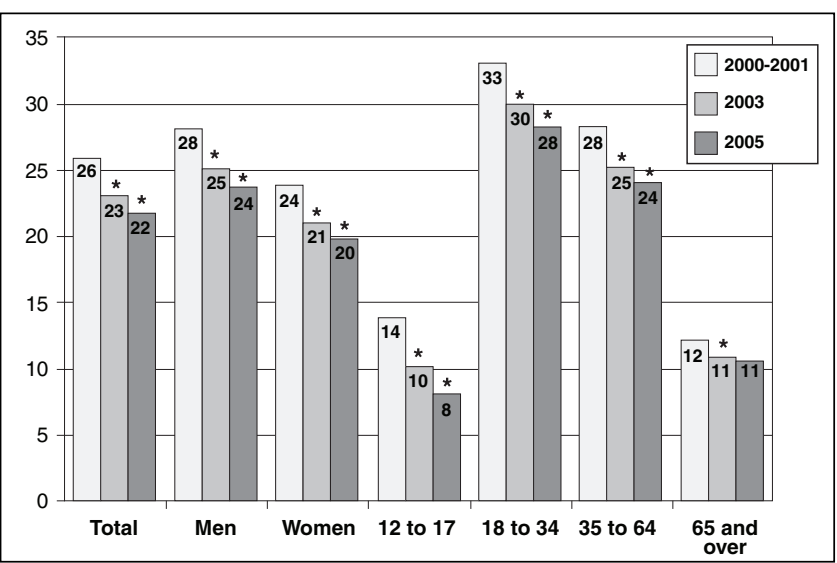

Figure 5) Percentage of current smokers aged 12 years or older in Canada 2000/2001 to 2005

The use of medication, including nicotine replacement therapy and the antidepressant bupropion, approximately doubles cessation rates and is recommended unless there are contraindications $(119,120)$ (level of evidence: 1A) (Table 7). Nicotine replacement therapy in conjunction with bupropion may have additive effects (121). A new nicotinic acetylcholine partial agonist, varenicline, has been shown to be more efficacious than bupropion or placebo (level of evidence: 1A). Varenicline has been shown to have superior short- and long-term efficacy compared with placebo (122126), as well as superior short-term efficacy compared with bupropion $(122,123)$. However, results showing varenicline's long-term benefit over bupropion are inconsistent after one year of follow-up $(122,123,125)$.

\section{Recommendation}

- Minimal interventions, lasting less than 3 minutes, should systematically be offered to every smoker with the understanding that more intensive counselling with pharmacotherapy results in the highest quit rates and should be used whenever possible (level of evidence: 1A).

\section{PHARMACOTHERAPY IN COPD}

Bronchodilators currently form the mainstay of pharmacological therapy for COPD (Figure 6). Bronchodilators work by decreasing airway smooth muscle tone, thus improving expiratory flow and lung emptying and reducing hyperinflation. Little information exists concerning the efficacy of pharmacotherapy in patients with milder COPD (ie, $\mathrm{FEV}_{1}$ greater than $65 \%$ predicted), making evidence-based guidelines for this subpopulation impossible. Evidence supporting the use of three classes of bronchodilators in COPD, as well as the combination products, is summarized below.

- Short-acting bronchodilators, both anticholinergics and beta ${ }_{2}$-agonists, have been shown to improve pulmonary function, dyspnea and exercise performance in patients with moderate to severe COPD (127-135). They have not been shown to have a consistent impact on quality of life. Individual responses to the different classes are variable.

- In short-term efficacy studies, the use of short-acting anticholinergic and beta $_{2}$-agonists together produces 
TABLE 7

Pharmacological aids to smoking cessation

\begin{tabular}{|c|c|c|}
\hline Medication & Dosage & $\begin{array}{l}\text { Duration, use } \\
\text { and advantage }\end{array}$ \\
\hline \multicolumn{3}{|c|}{ Nicotine gum } \\
\hline Nicorette & $\begin{array}{l}2 \mathrm{mg} \text { gum } \\
\text { if }<25 \text { cigarettes/day } \\
\text { maximum 24/day }\end{array}$ & $\begin{array}{l}\text { Up to } 12 \text { weeks but longer if required. One } \\
\text { piece of gum per hour or as needed. Chew } 2 \text { to } \\
3 \text { times and park gum between gingiva } \\
\text { and cheek for } 30 \mathrm{~s} \text { to } 60 \mathrm{~s} \text {; repeat this process fo } \\
30 \mathrm{~min} \text {. Do not eat or drink } 15 \text { min before or } \\
\text { after to allow nicotine absorption. }\end{array}$ \\
\hline $\begin{array}{l}\text { Nicorette } \\
\text { Plus }\end{array}$ & $\begin{array}{l}4 \text { mg gum if } \geq 25 \text { cigarettes/ } \\
\text { day; maximum } 24 / \text { day }\end{array}$ & Delays weight gain while being used. \\
\hline \multicolumn{3}{|c|}{ Nicotine patch } \\
\hline $\begin{array}{l}\text { Nicoderm } \\
\text { or }\end{array}$ & $\begin{array}{l}21 \mathrm{mg} / 24 \mathrm{~h} \\
14 \mathrm{mg} / 24 \mathrm{~h}\end{array}$ & $\begin{array}{l}4 \text { weeks } \\
2 \text { weeks }\end{array}$ \\
\hline Habitrol & $7 \mathrm{mg} / 24 \mathrm{~h}$ & $\begin{array}{l}2 \text { weeks } \\
\text { If <10 cigarettes/day start with lower dose. } \\
\text { Tapering and duration should be individualized. } \\
\text { Place patch on relatively hairless location } \\
\text { typically between neck and waist. }\end{array}$ \\
\hline \multicolumn{3}{|c|}{ Nicotine inhaler } \\
\hline $\begin{array}{l}\text { Nicorette } \\
\text { Inhaler }\end{array}$ & $\begin{array}{l}10 \mathrm{mg} / \text { cartridge/20 } \mathrm{min}, \\
6 \text { to } 12 \text { cartridges/day }\end{array}$ & $\begin{array}{l}\text { Use frequent continuous puffing x } 20 \text { min each } \\
\text { cartridge or as needed. Use up to } 12 \text { weeks then } \\
\text { decrease progressively over } 6 \text { to } 12 \text { weeks. } \\
\text { Do not eat or drink } 15 \text { min before or after } \\
\text { to allow nicotine absorption. }\end{array}$ \\
\hline
\end{tabular}

\section{Bupropion}

Zyban

\section{Varenicline}

Champix

\begin{abstract}
$150 \mathrm{mg}$ PO QAM $\times 3$ days, $150 \mathrm{mg}$ PO BID after. At least $8 \mathrm{~h}$ between two successive doses. In case of insomnia, the second dose should not be taken as close to bedtime; if insomnia persists, reduce dosage to $150 \mathrm{mg}$ every morning. Decrease dosage with hepatic or renal failure.
\end{abstract}

7 to 12 weeks. Smoking cessation advised between days 8 and 14. Monitor blood pressure if used with NRT. Consider longer treatment for smokers who are subject to significant mood swings or who continue to experience strong urges to smoke after discontinuing bupropion. Decreases weight gain while being used.

\author{
Recent myocardial infarction*; \\ unstable angina*; severe \\ cardiac arrhythmia*; recent stroke
}

Pregnancy and breast feeding ${ }^{\dagger}$; patients $<18$ years

Recent myocardial infarction*; unstable angina*; severe

cardiac arrhythmia*; recent

stroke; pregnancy and breast

feeding ${ }^{\dagger}$; patients $<18$ years;

allergy to tape; generalized

skin disease

Hypersensitivity to menthol; recent myocardial infarction*; unstable angina*; severe cardiac arrhythmia*; recent stroke; pregnancy and breast feeding ${ }^{\dagger}$; patients $<18$ years; caution if asthma or reactive airways disease or COPD

Current seizure disorder; current or prior diagnosis of bulimia or anorexia nervosa; use of another medication containing bupropion such as Wellbutrin, an antidepressant; undergoing abrupt withdrawal from alcohol or benzodiazepines or other sedatives; known hypersensitivity to bupropion; current use of antidepressants of the monamine oxidase inhibitors or thioridazine within 14 days of discontinuation; not recommended in patients with severe hepatic impairment; caution in situations that may reduce seizure threshold $d^{\ddagger}$ and drug interactions $\S$

Allergy to varenicline; end-stage rena disease; in patients with severe renal impairment, the concomitant use of varenicline and cimetidine should be avoided; pregnancy and breast feeding; patients < 18 years; caution because of lack of experience $\pi$; safety and efficacy of varenicline in combination with other smoking cessation

\section{Burning, jaw} pain, hiccups
Adverse

effects
Local skin reaction, vivid dreams

Mouth and throat irritation, cough, rhinitis, taste changes, bronchospasm
Insomnia, dry mouth, tremors, skin rashes, serious allergic reactions

\footnotetext{
$0.5 \mathrm{mg} P \mathrm{PO}$ once a day for days 1 to $3 ; 0.5 \mathrm{mg}$ PO BID for days 4 to $7 ; 1.0 \mathrm{mg} \mathrm{PO}$ BID for days 8 to end of treatment. For patients with severe renal impairment ( $\mathrm{CrCl}<30 \mathrm{~mL} / \mathrm{min}$ ) dose adjustment to a maximum of $0.5 \mathrm{mg} \mathrm{BID}$ is recommended.
}

12 weeks. Stop smoking after 7 days.

Those who are still abstinent at 12 weeks may continue another 12 weeks of treatment. 
TABLE 7 - CONTINUED

Pharmacological aids to smoking cessation

\begin{tabular}{|c|c|c|c|c|}
\hline Medication & Dosage & $\begin{array}{l}\text { Duration, use } \\
\text { and advantage }\end{array}$ & Contraindications & $\begin{array}{l}\text { Adverse } \\
\text { effects }\end{array}$ \\
\hline
\end{tabular}

Varenicline - continued

Champix Because elderly patients are

more likely to have

therapies (ie, bupropion, NRT) have

decreased renal function,

not been studied. The concomitant use of

the dose should be chosen carefully and

NRT with varenicline may result in

it may be useful to monitor their

an increase in adverse reactions.

renal status. Dosing may be

reduced for patients who

experience intolerable adverse events.

*Nicotine replacement therapy (NRT) should be used with caution among particular cardiovascular patient groups: those in the immediate (within two weeks) postmyocardial infarction period, those with serious arrhythmias, and those with serious or worsening angina pectoris (119); ${ }^{\dagger}$ Many experts believe that the use of NRT is preferable to smoking during pregnancy $(119,362) ; ~ ¥$ History of head trauma or prior seizures, central nervous system tumour, excessive use of alcohol, addiction to opiates, cocaine or stimulants, use of over-the-counter stimulants or anorectics, diabetes treated with hypoglycemics or insulin, medications that lower the seizure threshold (theophylline, systemic steroids, antipsychotics and antidepressants, quinolones, antimalarials, lithium, amantadine, levodopa), St John's wort (119,121, 363-365); §See product monograph for complete list of possible drug interactions; \No clinical experience with patients with epilepsy, irritable bowel or other gastrointestinal problems, patients exposed to chemotherapy and, in general, patients with heart disease or chronic obstructive pulmonary disease (COPD). Since smoking cessation can exacerbate underlying psychiatric illness, care should be taken in patients with a history of psychiatric illness. May cause dizziness and somnolence, and patients should avoid driving or operating dangerous machines until they are certain that varenicline does not affect them adversely (366). Champix Pfizer Canada Inc; Nicorette and Nicoderm - Johnson \& Johnson Inc; Habitrol - Novartis Consumer Health Canada Inc; Wellbutrin - Biovail Pharmaceuticals; Zyban - Biovail Pharmaceuticals. BID Twice daily; CrCl Creatinine clearance; PO By mouth; QAM Every morning

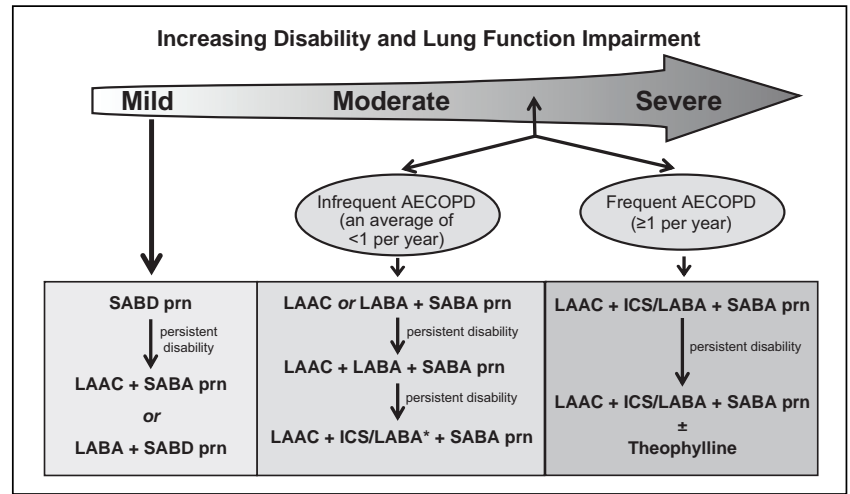

Figure 6) Recommendations for optimal pharmacotherapy in chronic obstructive pulmonary disease (COPD). *The inhaled corticosteroid/ long-acting beta -agonist (ICS/LABA) combination with the lower ICS dose should be used for patients with infrequent acute exacerbations of COPD (AECOPD). LAAC Long-acting anticholinergic; prn

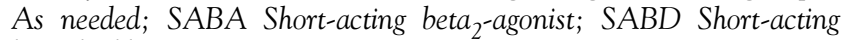
bronchodilator

superior bronchodilation than either drug does alone in patients with moderate to severe disease $(136,137)$.

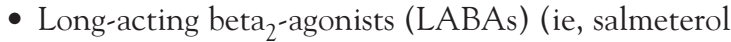
[SALM] or formoterol [FM]) offer more sustained improvements in pulmonary function, chronic dyspnea and quality of life than short-acting bronchodilators in patients with moderate to severe COPD. However, the effects of LABAs on exercise performance have been inconsistent (138-145). In the TORCH study (see below) (36), SALM therapy alone was not associated with reduced mortality, but was associated with reduced frequency and severity of exacerbations compared with placebo.

- The long-acting anticholinergic (LAAC) tiotropium bromide has been shown to have more sustained effects on pulmonary function, chronic activity-related dyspnea and quality of life than regular dose ipratropium bromide ( $40 \mu \mathrm{g}$ four times daily) or placebo in patients with moderate to severe COPD (146-149). Tiotropium provided consistent improvements in lung hyperinflation, exercise endurance, exacerbations and health resource utilization, when compared with placebo in patients with moderate to severe COPD $(79,80,150,151)$. When compared with LABA, tiotropium provided marginally greater improvements in lung function than SALM $(149,152)$. At this time, there is no published research comparing the long-term effects of tiotropium versus combination therapy with LABA and ICS. However, small short-term studies have shown that tiotropium provided either comparable (153) or greater (154) improvements in lung function than the combination of LABA and ICS.

- Combined long-acting bronchodilators: two small, short-term studies $(152,155)$ have provided evidence that the combination of LAAC (tiotropium) and LABA bronchodilators (FM) may have additive sustained effects on pulmonary function (improved expiratory flow rates and lung hyperinflation) in patients with moderate to severe COPD. In a recent one-year Canadian study (156), the addition of SALM to tiotropium in patients with more advanced COPD was associated with consistent improvement in health status but not with significant improvement in spirometry or reduction in the frequency and severity of exacerbation compared with tiotropium alone.

- Oral theophyllines are relatively weak bronchodilators, and offer modest improvements in pulmonary function, dyspnea and exercise performance. The addition of oral theophyllines to inhaled bronchodilator therapy may offer additive benefits in some patients, although the evidence evaluating theophylline in combination with long-acting bronchodilators is very limited (157-162). 
- ICS as monotherapy: short-term studies (163-166) examining the effects of ICS on the inflammatory process in COPD have yielded inconsistent results. Several studies have shown that ICS did not appear to have consistent effects on $\mathrm{FEV}_{1}$, symptoms and healthrelated quality of life (HRQL) in patients with severe COPD (167). A study by Paggiaro et al (168) found that in patients with chronic bronchitis and mild airflow obstruction (who had a history of at least one exacerbation per year for the past three years), ICS therapy significantly reduced the severity, but not the number, of exacerbations over this time period. Randomized clinical trials (RCTs) have not shown any effect on the relentless decline in lung function in patients with mild to severe COPD (169-172) (level of evidence: $1 \mathrm{E}$ ). ICSs have been shown to reduce exacerbations, although analysis of clinical trials which failed to consider between-patient variability in the number of exacerbations per year and failed to follow up patients who did not complete the study (eg, because of exacerbations) make final conclusions about clinical efficacy difficult (173). In the TORCH study (36), those randomized to ICS (fluticasone [FP]) alone did not show clinically significant effects on mortality compared to placebo. However, pulmonary function, exacerbation frequency and health status were all statistically improved compared with placebo therapy. It should be noted that the effects of FP on lung function, exacerbation frequency and health status were very modest, and although these effects were statistically significant compared with placebo, the clinical significance of these small improvements seen in the TORCH study is debatable.

- ICS/LABA combinations: two combination ICS and LABA products are currently available in Canada: FP plus SALM, and budesonide (BUD) plus FM. There is scientific evidence supporting a biological rationale: the combination of SALM/FP was associated with a reduction in key inflammatory cells and some markers of airway inflammation in mucosal biopsies of COPD patients compared with placebo (174). This antiinflammatory effect of the combination therapy (SALM/FP) was not demonstrated in mucosal biopsies of COPD patients treated with ICS (FP) alone (175). SALM/FP (50/250 $\mu$ g twice daily) was found to have superior effects on pulmonary function (both before [trough] and after dosing) compared with each component alone in patients with moderate to severe COPD (176). A RCT (145) showed that lower dose SALM/FP (50/250 $\mu$ g twice daily) was associated with consistent improvements in lung hyperinflation and exercise endurance compared with placebo. While demonstrating benefit, the prior results of six RCTs comparing combination therapy (both SALM/FP and FM/BUD) with the monocomponents alone did not provide definitive conclusions with respect to relative efficacy for a primary outcome measure of reduction in exacerbations (177). However, two recent RCTs, the TORCH study (36) and the Optimal Therapy study (163), have advanced understanding in this area. The TORCH trial (36) included 6112 patients $\left(\mathrm{FEV}_{1}\right.$ less than $60 \%$ of predicted value) in 42 countries. The study compared combined ICS and LABA (SALM/FP) with placebo, and ICS or LABA used alone. Mortality for the three-year study period was assessed in all patients (except for one missing patient), including those patients who dropped out. Secondary outcomes included $\mathrm{HRQL}, \mathrm{FEV}_{1}$ and exacerbations.

The probability of all-cause mortality at three years was $15.2 \%$ in the placebo group and $12.6 \%$ in the SALM/FP group (17\% relative reduction or $2.6 \%$ absolute risk reduction); the adjusted HR was 0.825 with a $95 \% \mathrm{CI}$ of 0.681 to 1.002 ( $\mathrm{P}=0.052$ ), which did not reach the prespecified statistical significance value of $\mathrm{P}<0.05$. This study also demonstrated that the treatment with SALM/FP significantly improved secondary outcome measures (exacerbation reduction, improved lung function and health status) in comparison with the placebo group. More importantly, treatment with SALM/FP statistically reduced exacerbation frequency, improved lung function and improved health status compared with SALM and FP alone.

The Optimal Therapy study (156) was a randomized, double-blind, placebo-controlled trial that studied the effectiveness of adding SALM or SALM/FP to therapy with tiotropium for the treatment of patients with moderate and severe COPD $\left(\mathrm{FEV}_{1}\right.$ less than $65 \%$ of the predicted value). Although the study did not show that the addition of SALM/FP to tiotropium significantly improved overall exacerbation rates (primary outcome), significant benefits were demonstrated on secondary outcomes (lung function, quality of life and hospitalization rates).

Another recent study (178) demonstrated that combination therapy with SALM/FP compared with SALM monotherapy reduces the frequency of moderate to severe exacerbations in patients with severe COPD.

\section{Drug safety}

Adverse effects of anticholinergics: Inhaled anticholinergic drugs are generally well tolerated. A bitter taste is reported by some using ipratropium. Occasional prostatic symptoms with urinary retention have been reported. The use of wet nebulizer solutions with a face mask can precipitate glaucoma if the drug gets directly into the eye. In clinical trials, tiotropium has been associated with a dry mouth in $12 \%$ to $16 \%$ of patients; however, less than $1 \%$ of patients withdrew from the trial due to this side effect. Urinary retention occurred in $0.73 \%$ of patients taking tiotropium; urinary tract infection occurred in $7.3 \%$ of patients taking tiotropium, compared with $5.1 \%$ of patients taking placebo $(146,147)$. Supraventricular tachy-arrhythmias are reported at a rate of between $0.1 \%$ and $1 \%$ greater with tiotropium than placebo (tiotropium bromide product monograph). Available information on the pharmacokinetics of the LAAC tiotropium suggest that the addition of short-acting anticholinergics (ipratropium bromide, combination ipratropium bromide and salbutamol) should not result in additional benefits in terms of increased bronchodilation but may instead predispose patients to significant adverse effects (179).

Adverse effects of beta ${ }_{2}$-agonists: Inhaled beta ${ }_{2}$-agonists are generally well tolerated. The most common adverse effects 
involve the cardiovascular system and the central nervous system. Cardiovascular effects include tachycardia, palpitation and flushing. Extrasystoles and atrial fibrillation may also be seen. In patients with coronary artery disease, beta 2 -agonists may induce angina. Central nervous system effects include irritability, sleepiness and tremor. Other adverse effects of beta ${ }_{2}$ agonists may include gastrointestinal upset, nausea, diarrhea, muscle cramps and hypokalemia (143). The TORCH study (36) confirmed the safety of SALM therapy in patients with moderate to severe COPD over the three-year period of the study.

Adverse effects of ICS, alone or in combination: Adverse effects of ICS include dysphonia and oral candidiasis (180182). ICS in doses greater than $1.5 \mathrm{mg} /$ day of beclomethasone equivalent may be associated with a reduction in bone density $(183,184)$. Long-term high doses of ICS are associated with posterior subcapsular cataracts, and, rarely, ocular hypertension and glaucoma (185-187). Skin bruising is also common with high-dose exposure $(169,170,172)$. In the TORCH study, the probability of having pneumonia was significantly higher among patients receiving ICS compared with placebo (19.6\% in the SALM/FP group, $18.3 \%$ in the FP group and $12.3 \%$ in the placebo group) (36). In a recent large cohort study, a dose-related increase in the risk of pneumonia requiring hospitalization was also found among patients using ICS (188).

\section{Recommendations (Figure 6)}

- For patients with symptoms that are only noticeable with exertion and who have relatively little disability, initiation of short-acting bronchodilator therapy, as needed, is acceptable. Options would include shortacting beta ${ }_{2}$-agonists or short-acting anticholinergics, alone or in combination. The choice of first-line therapy in mild symptomatic COPD should be individualized and based on clinical response and tolerance of side effects. Some such patients may benefit from treatment with a long-acting bronchodilator (level of evidence: 3B).

- For patients with more persistent symptoms and moderate to severe airflow obstruction, a long-acting bronchodilator such as tiotropium or SALM should be used to improve dyspnea, exercise endurance and health status and to reduce exacerbation frequency (level of evidence: $1 \mathrm{~A}$ ). Short-acting beta ${ }_{2}$-agonists should be used as needed for immediate symptom relief. The panel believed that tiotropium was an acceptable first choice long-acting bronchodilator in this group given its proven clinical efficacy, convenient once-daily dosing regimen and safety profile (level of evidence: 3B).

- For patients with moderate to severe COPD with persistent symptoms but infrequent exacerbations (less than one per year, on average, for two consecutive years), a combination of tiotropium $18 \mu$ once daily and a LABA (ie, SALM $50 \mu \mathrm{g}$ twice daily) is recommended to maximize bronchodilation and lung deflation (level of evidence: 3B). Lower dose SALM/FP (50/250 $\mu$ twice daily) could be substituted for SALM to maximize bronchodilation in patients with persistent dyspnea despite combined long-acting bronchodilators
(SALM plus tiotropium) (level of evidence: 3B). Short-acting beta 2 -agonists may be used as needed for immediate symptom relief.

- For patients with moderate to severe COPD with persistent symptoms and a history of exacerbations (one or more per year, on average, for two consecutive years), a combination of tiotropium plus a LABA and ICS therapy product (eg, SALM/FP 50/500 $\mu$ g twice daily or FM/BUD $12 / 400 \mu g$ twice daily) is recommended to improve bronchodilation and lung deflation, to reduce the frequency and severity of exacerbations and to improve health status (level of evidence 1A). Shortacting beta 2 -agonists may be used as needed for immediate symptom relief.

- ICS should not be used as monotherapy in COPD and when used should be combined with a LABA (level of evidence: $1 \mathrm{E}$ ).

- In patients with severe symptoms despite use of both tiotropium and a LABA/ICS, a long-acting preparation of oral theophylline may be tried, although monitoring of blood levels, side effects and potential drug interactions is necessary (level of evidence: $3 \mathrm{~B}$ ).

Case 1

\section{CASE SCENARIOS}

Case 1 is a 57 -year-old woman with COPD. She complains of dyspnea only with heavier exertion such as climbing stairs or dancing. She is not short of breath walking on level ground. Her $\mathrm{FEV}_{1}$ is $80 \%$ predicted post bronchodilator.

Assessment: This patient has MRC grade 2 dyspnea (mild exertional limitation) and mild airflow obstruction.

Suggested therapy: The initiation of a rapid-onset, shortacting bronchodilator to be used as needed is suggested. The patient should be prescribed a short-acting beta 2 -agonist (eg, salbutamol) or a short-acting anticholinergic (eg, ipratropium bromide), two to three puffs every $4 \mathrm{~h}$ as needed, or both, for dyspnea relief. With persistent symptoms requiring frequent use of short-acting bronchodilators, a long-acting bronchodilator could be added.

\section{Case 2}

Case 2 is a 67-year-old man with COPD. He complains of dyspnea when walking $50 \mathrm{~m}$ to $75 \mathrm{~m}$ on level ground at a slow pace. He has no history of COPD exacerbations during the past two years. His $\mathrm{FEV}_{1}$ is $55 \%$ of predicted.

Assessment: This patient has MRC grade 4 dyspnea (moderate exertional limitation) and moderate airflow obstruction.

\section{Suggested therapy:}

First step: Initiation of a long-acting anticholinergic (eg, tiotropium) or a long-acting beta ${ }_{2}$-agonist (eg, salmeterol or formoterol). Short-acting beta 2 -agonists should be used as needed for immediate symptom relief.

Second step: If patient is still dyspneic after initiation of the above, then a combination of two long-acting bronchodilators is recommended to maximize symptom relief. In the event that symptoms persist despite combining inhaled long-acting bronchodilators, consideration should be given to replacing the LABA with lower dose LABA/ICS combination (eg, SALM/FP or FM/BUD). 


\section{Case 3}

Case 3 is a 62-year-old woman with COPD. She complains of dyspnea when combing her hair or getting dressed. She is unable to walk more than $25 \mathrm{~m}$ because of dyspnea. She has had three COPD exacerbations in the past two years that have required treatment with antibiotics and/or systemic corticosteroids. Her $\mathrm{FEV}_{1}$ is $35 \%$ of predicted.

Assessment: This patient has MRC grade 5 dyspnea (severe exertional limitation) and severe airflow obstruction.

Suggested therapy:

First step: Initiation of long-acting anticholinergic (eg, tiotropium once daily), plus a combination LABA/ICS product (eg, SALM/FP or FM/BUD)twice daily. Short-acting beta $_{2}$-agonists should be used as needed for immediate symptom relief.

Second step: If the patient is still dyspneic after initiation of the above, then consider adding a long-acting theophylline preparation, with monitoring of blood levels, side effects and potential drug interactions.

\section{Oral corticosteroids}

Several short-term trials have been reported over the past 50 years. A meta-analysis (189) based on 15 studies meeting pre-established quality criteria was performed in 1991. Improvement of at least $20 \%$ of the $\mathrm{FEV}_{1}$ from baseline was set as the clinically meaningful difference. It was estimated that only $10 \%$ of patients with stable COPD benefit from oral corticosteroids in the short term based on this operational definition (95\% CI 18\%) (190).

Adverse effects of oral steroids: The benefits of maintenance oral corticosteroid therapy must be weighed against the risk of adverse events. Adverse events are numerous and include adrenal suppression, osteoporosis, cataract formation, dermal thinning, muscle weakness, hypertension, diabetes, psychosis and hyperadrenocorticism (191-195).

\section{Recommendation}

- Long-term treatment with oral corticosteroids should not be used in COPD, given the absence of benefit and the high risk of adverse systemic effects (level of evidence: $1 \mathrm{E})$.

\section{ACUTE EXACERBATIONS OF COPD (AECOPD)}

AECOPD is defined as a sustained worsening of dyspnea, cough or sputum production leading to an increase in the use of maintenance medications and/or supplementation with additional medications (level of evidence: 3 ). The term 'sustained' implies a change from baseline lasting $48 \mathrm{~h}$ or more. In addition, exacerbations should be defined as either purulent or nonpurulent because this is helpful in predicting the need for antibiotic therapy (level of evidence: 2A).

Acute exacerbations are the most frequent cause of medical visits, hospital admissions and death among patients with COPD (196). In addition, frequent exacerbations are an important determinant of quality of life in this group of patients $(197,198)$ and contribute to accelerated rates of decline in lung function (199). AECOPD are often under-recognized and under-reported by patients, leading to prolonged periods of symptoms and marked impairment in quality of life (200).

The average COPD patient experiences approximately two exacerbations per year but this is highly variable and as many as
TABLE 8

Potential preventive strategies for acute exacerbations of chronic obstructive pulmonary disease (AECOPD)

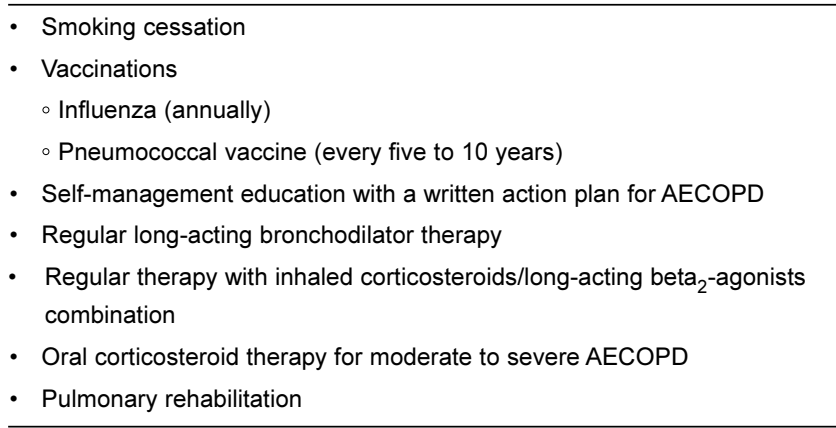

$40 \%$ of individuals with COPD may not have any exacerbations. Exacerbations are related to the severity of underlying airflow obstruction: patients with a lower $\mathrm{FEV}_{1}$ have more frequent and more severe exacerbations (201). Patients with mild to moderate disease have a $4 \%$ short-term mortality rate if admitted to hospital $(199,202)$, but mortality rates can be as high as $24 \%$ if patients are admitted to an intensive care unit (ICU) with respiratory failure (203-206). In addition, this group of patients requiring ICU admission has a one-year mortality rate as high as $46 \%$. A significant percentage of patients requiring hospitalization for AECOPD require subsequent readmissions because of persistent symptoms, and experience at least a temporary decrease in their functional abilities following discharge $(203,207,208)$.

At least one-half of AECOPD are thought to be infectious in nature. Many of these are initially viral in origin and the remainder are due to bacterial infection. Other triggering factors for exacerbations include congestive heart failure, exposure to allergens and irritants (ie, cigarette smoke, dust, cold air or pollutants) and pulmonary embolism (209).

\section{Prevention of AECOPD (Table 8)}

- Smoking cessation reduces the rate of lung function decline and may in this manner reduce the risk for AECOPD $(63,64,210)$. However, direct evidence of an association between smoking cessation and reduction in AECOPD is not available.

- COPD patients infected with influenza have a significant risk of requiring hospitalization. An annual influenza vaccination reduces morbidity and mortality from the disease by as much as $50 \%$ in the elderly and reduces the incidence of hospitalization by as much as 39\% in patients with chronic respiratory conditions $(211,212)$.

- The benefit of pneumococcal vaccine in COPD is less well established. Some reports state that the vaccine has up to a $65 \%$ efficacy in COPD patients (213), although an effect on reducing the frequency of AECOPD has yet to be established. A recent report (214) demonstrated a reduction in the prevalence of community-acquired pneumonia in a subgroup of COPD patients younger than 65 years of age who received the pneumococcal vaccine.

- A comprehensive self-management education program may be associated with a reduction in the frequency and/or severity of AECOPD and thereby reduce economic costs $(115,215-217)$. 
- There is some evidence to suggest that COPD patients treated with LABAs or the LAAC agent tiotropium have either fewer AECOPD or a delayed time to their next exacerbation compared with patients receiving either placebo or ipratropium bromide $(150,151,218$ 221).

- Chronic therapy with ICS may reduce the frequency of AECOPD (36,169,172,219,222-226), although this effect is not clear and has recently been questioned $(173,227,228)$. The TORCH study (36) demonstrated that FP alone when administered to patients with moderate to severe COPD was less effective than SALM/FP combination in reducing the frequency and severity of acute exacerbations.

- Regular therapy with the combination of SALM and FP in the same inhaler has been demonstrated to significantly reduce the frequency of AECOPD (a secondary outcome in this study) by $25 \%$ compared with placebo in patients with an $\mathrm{FEV}_{1}$ less than $60 \%$ predicted (36). Other smaller, shorter duration studies that have compared the effect of combined LABA/ICS with that of placebo on exacerbations in COPD have generally found superiority for the active treatment, but methodological and statistical issues preclude definitive conclusions $(219,223,224,227)$.

- The Optimal Therapy Trial study (156) examined the effect of combining tiotropium with SALM/FP on the frequency of all exacerbations in patients with advanced COPD and did not find any added benefit of the two treatments over tiotropium therapy alone. However, hospitalization rates were significantly reduced in those receiving SALM/FP plus tiotropium compared with tiotropium alone.

- Short-term therapy with oral prednisone following emergency department treatment for AECOPD has recently been demonstrated to reduce the likelihood of patients relapsing with another AECOPD (229).

- Some studies have demonstrated that pulmonary rehabilitation in patients with advanced COPD is associated with reductions in the number of exacerbations and hospitalizations in patients with COPD (230-235).

- Currently, there is no evidence to support the use of prophylactic antibiotics in the prevention of AECOPD.

\section{Recommendations}

- Annual influenza vaccination is recommended for all COPD patients who do not have a contraindication (level of evidence: 2A).

- Pneumococcal vaccination should be given to all COPD patients at least once in their lives; in high-risk patients, consideration should be given to repeating the vaccine in five to 10 years (level of evidence: $3 \mathrm{C}$ ).

- Patients with an $\mathrm{FEV}_{1}$ less than $60 \%$ predicted should be considered for treatment with tiotropium with or without a LABA (level of evidence: 1A).
- ICSs as monotherapy should not be prescribed for the purpose of reducing exacerbations in COPD (level of evidence: $1 \mathrm{E}$ ).

- Patients with an $\mathrm{FEV}_{1}$ less than $60 \%$ predicted and who experience one or more AECOPD per year should be considered for treatment with the combination of a LABA and an ICS (level of evidence: 1A).

\section{Management of acute exacerbation}

Diagnostic evaluation: A complete history and physical examination should be performed to rule out other causes for worsening cough and dyspnea. In one recent study (236), pulmonary embolism was found in up to $25 \%$ of patients hospitalized with unexplained exacerbation and should therefore be considered in this setting.

- Arterial blood gases should be performed in a subset of patients who have low arterial oxygen saturations on oximetry.

- Chest $\mathrm{x}$-rays are recommended for patients presenting to the emergency department or for admission to hospital because they have been shown to reveal abnormalities that lead to a change in management in $16 \%$ to $21 \%$ of patients $(237,238)$ (level of evidence: 2B).

- For patients presenting with purulent sputum, the role for sputum Gram stain and culture remains undefined. Gram stain and culture should be considered for patients with very poor lung function, frequent exacerbations or who have been on antibiotics in the preceding three months (level of evidence: $3 \mathrm{C}$ ).

- Pulmonary function tests should be performed in patients suspected of having COPD following recovery, if they have not previously had spirometry (level of evidence: 3C).

Bronchodilators: Inhaled bronchodilators should be used to improve airway function and reduce lung hyperinflation, thus relieving dyspnea in AECOPD (level of evidence: 2A). Combined short-acting beta 2 -agonist and anticholinergic inhaled therapy is recommended in the acute situation (239. 242) (level of evidence: 3C). A role for initiation of therapy with long-acting bronchodilators appears promising but there is insufficient evidence to allow for firm recommendations at this time (243).

Corticosteroid therapy: There is good evidence to support the use of oral or parenteral corticosteroids in most patients with moderate to severe AECOPD (level of evidence: 1A) $(229,244-248)$. The exact dose and duration of therapy should be individualized, but treatment periods of between 10 and 14 days are recommended (level of evidence: 1A). Dosages of $30 \mathrm{mg}$ to $40 \mathrm{mg}$ of prednisone equivalent per day are suggested (level of evidence: 1A). Hyperglycemia is associated with poorer outcomes in patients admitted with AECOPD (249), so the risks and benefits of corticosteroid therapy must be considered in individual patients.

Antibiotics: Several randomized, placebo-controlled trials of antibiotic therapy have been performed in AECOPD (250. 258). Based on the results of these studies, it is recognized that antibiotics are beneficial in the treatment of more severe purulent AECOPD (259) (level of evidence: 1A). In the smaller subset of patients who produce only mucoid (white or clear) 
TABLE 9

Antibiotic treatment recommendations for purulent acute exacerbations of chronic obstructive pulmonary disease (COPD)

\begin{tabular}{|c|c|c|c|c|}
\hline Group & Basic clinical state & Symptoms and risk factors & Probable pathogens & First choice \\
\hline Simple & COPD without risk factors & $\begin{array}{l}\text { Increased cough and sputum, } \\
\text { sputum purulence, and } \\
\text { increased dyspnea }\end{array}$ & $\begin{array}{l}\text { Haemophilus influenzae, } \\
\text { Haemophilus species, } \\
\text { Moraxella catarrhalis, } \\
\text { Streptococcus pneumoniae }\end{array}$ & $\begin{array}{l}\text { Amoxicillin, doxycycline, trimethoprim/ } \\
\text { sulfamethoxazole, second- or third- } \\
\text { generation cephalosporins, extended- } \\
\text { spectrum macrolides }\end{array}$ \\
\hline Complicated & COPD with risk factors & $\begin{array}{l}\text { As in simple plus at least one of: } \\
\text { - } \mathrm{FEV}_{1}<50 \% \text { predicted } \\
\text { - } \geq 4 \text { exacerbations per year } \\
\text { - Ischemic heart disease } \\
\text { - Use of home oxygen } \\
\text { - Chronic oral corticosteroid use } \\
\text { - Antibiotic use in the past three months }\end{array}$ & $\begin{array}{l}\text { As in simple plus: } \\
\text { Klebsiella species and other } \\
\text { Gram-negatives } \\
\text { Increased probability of } \\
\text { beta-lactam resistance }\end{array}$ & $\begin{array}{l}\text { Beta-lactam/beta-lactamase inhibitor; } \\
\text { fluoroquinolone (antibiotics for } \\
\text { uncomplicated patients when } \\
\text { combined with oral steroids may suffice) }\end{array}$ \\
\hline
\end{tabular}

FEV 1 Forced expiratory volume in $1 \mathrm{~s}$

sputum during AECOPD, recovery usually occurs without antibiotics (260). Novel indicators of bacterial infection, such as serum procalcitonin, may soon help guide decisions regarding the need for antibiotic therapy (261).

Patients can be divided into two groups - simple or complicated exacerbations - based on the presence of risk factors that either increase the likelihood of treatment failure or are more likely to be associated with more virulent or resistant microbial pathogens (level of evidence: 3C) (Table 9). This approach to management of AECOPD has not been formally evaluated in clinical studies but nevertheless was considered to be a useful practical management guide by the Panel.

\section{Recommendation}

- Antibiotics should be considered for use in patients with purulent exacerbations (level of evidence: 1A).

\section{PULMONARY REHABILITATION}

Benefits of pulmonary rehabilitation

Pulmonary rehabilitation is the most effective therapeutic strategy for improving dyspnea, exercise endurance (Figure 7) and quality of life compared with standard care $(262,263)$. These improvements in dyspnea and exercise performance are largely attributable to the exercise training component of the rehabilitation program $(264,265)$, because education alone has no effect on these parameters $(114,266)$. Psychosocial support in the rehabilitation setting is also a key contributor to the success of such programs. No clinical trials have been designed and powered to study the impact of pulmonary rehabilitation on mortality. However, participation in a pulmonary rehabilitation program incorporating exercise training is associated with a trend toward reduced mortality rate compared with standard care alone $(114,232)$.

Exercise training modality

Evidence from several randomized, controlled trials is available to support the use of a lower extremity aerobic exercise training regimen for patients with COPD to improve exercise capacity, dyspnea and quality of life (263) (level of evidence: $1 \mathrm{~A})$. Incorporating strengthening exercises into the training regimen is also recommended. Compared with placebo, greater improvement in peripheral muscle strength and endurance, submaximal exercise capacity and quality of life have been

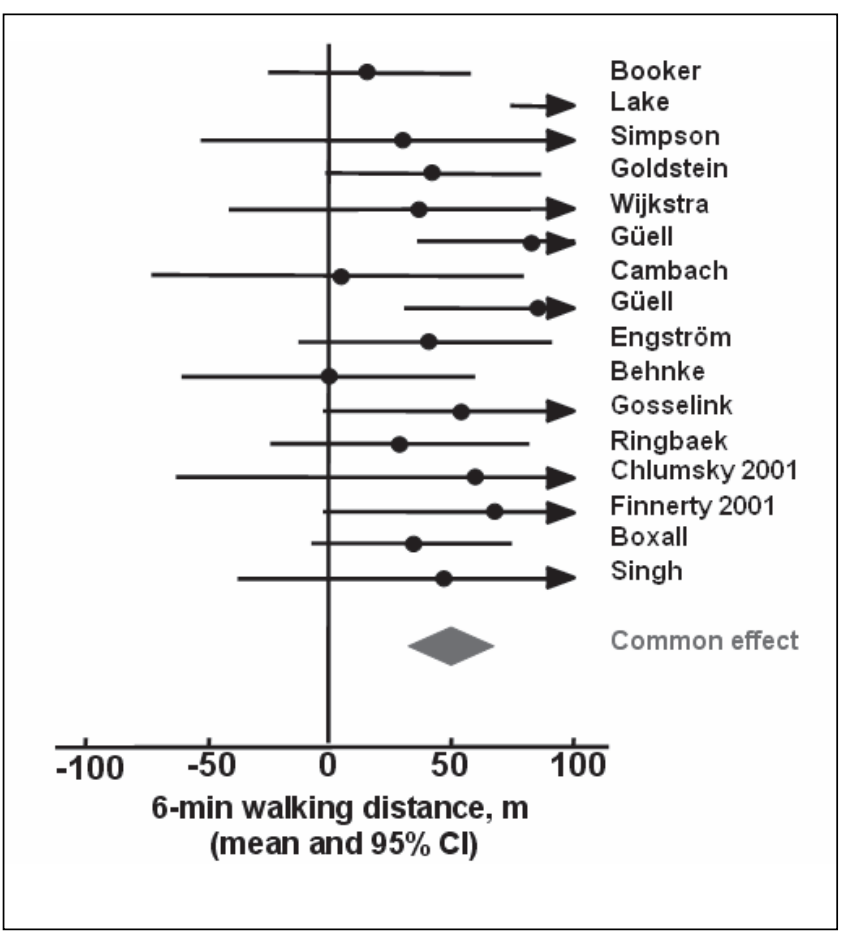

Figure 7) The effect of exercise training on 6 minute walk distance in chronic obstructive pulmonary disease $(n=669)$ as summarized in the meta-analysis of Lacasse et al (263)

shown with strength exercises in patients with COPD and a wide range of disease severity (267-269) (level of evidence: 1A). These benefits of strength training can be obtained in a safe and well-accepted manner by the participants (267-269). The gains in muscle strength are greater with muscle training than with endurance training (270-272), while the gain in endurance to constant workrate exercise are greater with endurance training compared with strength training alone $(271,273)$. Based on this, combining aerobic and strength training would appear to be an optimal rehabilitation strategy in patients with COPD (270-272). Whether the addition of strength training to endurance training translates into further improvement in exercise tolerance or quality of life has not been confirmed (270-272). 
The development of innovative ways to improve tolerance to high-intensity training is the subject of intense research. Different techniques such as interval training $(274,275)$, noninvasive ventilation (276,277), oxygen (278,279), heliox (280), and anabolic supplementation (281) have been used. Neuromuscular electrostimulation training has also been introduced as a possible rehabilitative strategy in patients with COPD (282-285). High-intensity training is associated with better physiological outcomes $(278,286,287)$. However, these greater physiological benefits do not automatically translate into larger gains in quality of life and other relevant clinical outcomes $(278,287)$. Further research is necessary to determine the optimal training intensity in patients with COPD.

\section{Rehabilitation following AECOPD}

Recent randomized controlled trials with long-term follow-up of patients after rehabilitation have shown a trend toward decreased hospital days, fewer exacerbations and more efficient primary care use (114,230-232). A recent meta-analysis (288) showed evidence from six RCTs that pulmonary rehabilitation is effective in COPD patients after acute exacerbations: risk for hospital admissions and mortality were reduced; and HRQL and exercise capacity were improved.

\section{Long-term effects of pulmonary rehabilitation}

The benefits of pulmonary rehabilitation (improved dyspnea, activity level and quality of life) are usually sustained for several months after the end of an exercise program $(114,230,289$. 292). However, initial improvement in these parameters is progressively lost after stopping exercise, highlighting the importance of incorporating a carefully supervised maintenance exercise program. AECOPD are recognized as having a negative influence on exercise maintenance programs in this population.

\section{Access to pulmonary rehabilitation programs}

Despite the proven benefits of pulmonary rehabilitation, a recent national survey revealed that only 98 programs exist in Canada. These programs combined have a capacity to serve only approximately $1.2 \%$ of the COPD population in Canada. Regional disparity in access to pulmonary rehabilitation was also highlighted in the survey: most programs were located in Ontario and Quebec, whereas some provinces (eg, Newfoundland, Prince Edward Island) had none (293). Strategies should be developed to improve availability of pulmonary rehabilitation at a lower cost. In this regard, selfmonitored home-based rehabilitation is a promising approach (294).

\section{Who to refer to pulmonary rehabilitation}

Criteria for referral to a pulmonary rehabilitation program include: clinically stable, symptomatic COPD; reduced activity levels and increased dyspnea despite pharmacological treatment; no evidence of active ischemic, musculoskeletal, psychiatric or other systemic disease; and sufficient motivation for participation. In North America, most patients enter rehabilitation at this late stage of their disease. Exercise training is too often considered as a last resort therapeutic modality; to minimize the consequences of COPD, it would be advisable to consider pulmonary rehabilitation as early as possible in the natural evolution of the disease.

\section{Cost-effectiveness of pulmonary rehabilitation}

The cost-effectiveness of pulmonary rehabilitation added to standard care has been compared with that of standard care alone in two large controlled, randomized clinical trials $(295,296)$. The direct and indirect costs related to healthcare delivery (including the cost related to the rehabilitation program) were compared in the two treatment arms. The general conclusion of these studies is that: the extra expenses associated with pulmonary rehabilitation are completely offset by the reduction in health care utilization costs; the costeffectiveness profile is better for outpatient than inpatient pulmonary rehabilitation; and pulmonary rehabilitation is highly cost-effective compared with many other interventions incorporated into routine clinical practice, such as hip replacement, coronary artery bypass graft and hemodialysis. This important information should spur the implementation of pulmonary rehabilitation in a broader basis across the country.

\section{Recommendations}

- All patients should be encouraged to maintain an active lifestyle and be cautioned about the negative consequences of prolonged inactivity in this disease (level of evidence: $3 \mathrm{~A}$ ).

- Clinically stable patients who remain dyspneic and limited in their exercise capacity despite optimal pharmacotherapy should be referred for supervised pulmonary rehabilitation (level of evidence: 1A).

- An urgent need exists to increase access to pulmonary rehabilitation programs across Canada (level of evidence: $2 \mathrm{~A}$ ).

\section{OXYGEN THERAPY FOR COPD}

The survival benefit of domiciliary oxygen has been documented by two large, randomized, controlled trials: the MRC and the Nocturnal Oxygen Therapy study groups $(297,298)$. Both studies were conducted in hypoxemic COPD patients (with a partial pressure of arterial oxygen $\left[\mathrm{PaO}_{2}\right] 60 \mathrm{mmHg}$ or less), most of whom were male. Taken together, these trials demonstrated that the benefits from long-term oxygen therapy (LTOT) are dose-dependent: the longer the exposure to supplemental oxygen, the larger the benefits in terms of survival.

\section{Recommendation}

- Long-term continuous oxygen (15 h/day or more to achieve a saturation of $90 \%$ or greater) should be offered to patients with stable COPD with severe hypoxemia $\left(\mathrm{PaO}_{2}\right.$ $55 \mathrm{mmHg}$ or less), or when $\mathrm{PaO}_{2}$ is less than $60 \mathrm{mmHg}$ in the presence of bilateral ankle edema, cor pulmonale or a hematocrit of greater than 56\% (level of evidence: $1 \mathrm{~A}$ ).

\section{Nocturnal oxygen}

Nocturnal oxygen desaturation in COPD has been suggested to increase mortality $(299,300)$. It has also been associated with poor sleep quality as indicated by reduced sleep time, increased sleep stage changes and increased arousal frequency (301). In two clinical trials $(299,300)$ and in a subsequent meta-analysis (302), nocturnal oxygen therapy was not shown to increase survival in COPD patients with 'isolated' nocturnal oxygen desaturation. It also has not been shown to be consistently effective in 


\begin{tabular}{lcc}
\hline Criteria suggesting benefit & Criteria suggesting lack of benefit & Contraindications \\
\hline Respiratory distress & Milder exacerbations & Respiratory arrest \\
Respiratory rate $>25$ breaths/min & $\mathrm{pH}>7.35$ \\
Use of accessory muscles & Mild respiratory distress \\
Respiratory acidosis & Very severe exacerbations \\
$\mathrm{pH}<7.35$ & $\mathrm{pH}<7.20$ \\
$\mathrm{PaCO}_{2}>45 \mathrm{mmHg}$ & Somnolence \\
& Lack of response to NPPV \\
& Increase or no change in respiratory rate \\
& Decrease or no change in pH \\
& Excessive secretions \\
\hline
\end{tabular}

NPPV Noninvasive positive pressure ventilation; $\mathrm{PaCO}_{2}$ Partial pressure of arterial carbon dioxide

improving sleep quality in these patients $(300,303,304)$. Moreover, because obstructive sleep apnea is common, there is a high likelihood that a few patients will have both conditions.

\section{Recommendation}

- There is currently no evidence to support the use of nocturnal oxygen to improve survival, sleep quality or quality of life in patients with isolated nocturnal desaturation (level of evidence: $1 \mathrm{C}$ ).

\section{Ambulatory oxygen}

Moderate hyperoxia during submaximal exercise testing increases exercise time, reduces exercise minute ventilation and dynamic lung hyperinflation, and may delay respiratory muscle dysfunction in patients with moderate to severe COPD (305-307). A number of recent short-term mechanistic studies have demonstrated that hyperoxia, either alone or combined with helium or bronchodilators, is associated with large improvements in exercise endurance and exertional dyspnea in patients without significant arterial oxygen desaturation (308-311). The acute improvements with hyperoxia are approximately double those achieved with bronchodilators alone; bronchodilators and hyperoxia have additive effects on dyspnea and exercise endurance (308). However, most patients do not benefit from ambulatory oxygen despite the acute benefits of oxygen therapy on exercise tolerance. Ambulatory oxygen has been used in patients with COPD with isolated exercise-induced oxygen desaturation and in patients with COPD with resting hypoxemia qualifying for LTOT. Studies performed in the former subset of patients demonstrate that the impact of ambulatory oxygen on quality of life and exercise is modest and not clinically important (312314). Similar conclusions have been reached in patients qualifying for LTOT $(315,316)$. Occasional responders to ambulatory oxygen have been reported $(313,314)$. However, identification of these patients is a challenge because the long-term response to ambulatory oxygen cannot be predicted from the acute exercise response to oxygen $(313,316)$.

\section{Recommendation}

- Current evidence does not justify the widespread provision of ambulatory oxygen to patients with COPD (level of evidence: 1C).

\section{NONINVASIVE POSITIVE PRESSURE VENTILATION}

Numerous randomized controlled trials and a recent systematic review support the benefit of noninvasive positive pressure ventilation (NPPV) in the setting of AECOPD (317-327). However, not all patients with COPD exacerbations benefit from NPPV (320,328-330) (Table 10). A combined nasal/oral (full face) mask is preferable and has been shown to be more comfortable (331).

Patients with advanced COPD who have been designated as Do Not Rescuscitate or Do Not Intubate can still be considered for NPPV: three studies suggest that hospital survival rates range from $50 \%$ to $60 \%$ in these patients (332-334). However, one-year survival of these patients may be as low as $30 \%$, and one-third of these patients are likely to require rehospitalization.

A large RCT on the use of NPPV in patients with AECOPD treated on a respiratory ward rather than the ICU reported a reduction in mortality for the group treated with NPPV for both those with severe ( $\mathrm{pH}$ less than 7.3) or less severe exacerbations (326). However, the mortality rate of the severe subgroup of patients treated on the ward with NPPV was higher than that reported in the literature for apparently similar patients treated in the ICU. As such, in patients with severe COPD exacerbations, NPPV should be initiated in a setting that provides adequate cardiopulmonary monitoring and personnel skilled at endotracheal intubation and invasive mechanical ventilation, should the patient fail NPPV (level of evidence: $2 \mathrm{~B}$ ).

A recent paper (335) concluded that there was insufficient evidence to recommend the use of NPPV in hypercapnic patients with stable COPD (ie, patients who are not currently exacerbating).

\section{Recommendations}

- NPPV should be considered in patients presenting with a severe exacerbation of COPD ( $\mathrm{pH}$ less than 7.3) (level of evidence: 1A).

- Patients with milder exacerbations do not benefit from NPPV.

- NPPV should be administered in a setting that allows close cardiopulmonary monitoring and access to 


\title{
TABLE 11
}

Selection criteria for lung volume reduction surgery

Indications
Disability from emphysema (not from bronchitis or asthma) despite
maximal medical treatment
Absence of clinically significant bronchiectasis and absence of
high daily sputum production
Abstinence from smoking for more than four months
FEV $1 \leq 45 \%$ predicted
TLC $\geq 100 \%$ predicted
RV $\geq 150 \%$ predicted
Upper lobe-predominant emphysema (heterogeneous emphysema)
6 minute walk distance $>140 \mathrm{~m}$

\author{
Contraindications \\ Comorbid disease (ie, with risk of life expectancy less than two years) \\ Severe obesity (body mass index $>31.1 \mathrm{~kg} / \mathrm{m}^{2}$ in men and $>32.3 \mathrm{~kg} / \mathrm{m}^{2}$ in \\ women) or cachexia \\ Severe coronary artery disease or other significant cardiac disorder \\ Giant bulla $\geq 1 / 3$ of lung in which bull is located \\ Oxygen requirement $>6 \mathrm{~L} / \mathrm{min}$ to maintain saturation $\geq 90 \%$ \\ Extensive pleural symphysis, eg, from pleural disease or previous chest surgery \\ Prednisone daily use of $>20 \mathrm{mg}$ \\ $\mathrm{PaCO}_{2}>60 \mathrm{mmHg}$ or $\mathrm{PaO}_{2}<45 \mathrm{mmHg}$ on room air \\ $\mathrm{PAP} \geq 35 \mathrm{mmHg}$ (mean) \\ $\mathrm{FEV}_{1} \leq 20 \%$ predicted and homogeneous distribution or $\mathrm{D}_{\mathrm{L}} \mathrm{CO} \leq 20 \%$ predicted
}

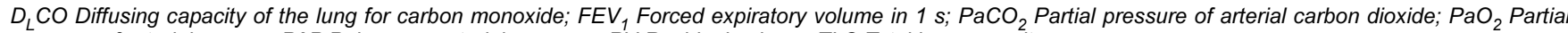
pressure of arterial oxygen; PAP Pulmonary arterial pressure; RV Residual volume; TLC Total lung capacity

personnel skilled at endotracheal intubation and invasive mechanical ventilation (level of evidence: 1A).

- NPPV is not indicated for patients who have had a respiratory arrest, who have hemodynamic instability, who are at high risk for aspiration, who have impaired mental status or who are otherwise unable to cooperate (level of evidence: 1E).

- NPPV for stable COPD patients with chronic hypercapnia is not currently recommended (level of evidence: 1C).

\section{LVRS}

\section{SURGERY}

Six randomized clinical trials have all reported better outcomes in the surgical arms three to 12 months after surgery (336-341). However, these trials did not include large numbers of patients $(n=37$ to $n=60)$. The results of larger trials with longer duration of follow-up are now available: the National Emphysema Treatment Trial (NETT) (342), the Overholt Blue-Cross Emphysema Surgery Trial (OBEST) (343) and the Canadian Lung Volume Reduction Trial (CLVRT) (344). The NETT initially established a subgroup of patients with emphysema who are harmed by LVRS (345) (level of evidence: 1E). Patients with an $\mathrm{FEV}_{1}$ less than $20 \%$ predicted and either homogeneous distribution emphysema or a diffusing capacity of no more than $20 \%$ predicted have higher mortality rates if they undergo LVRS.

Recent larger trials have reported improved $\mathrm{FEV}_{1}$ and reduced lung volumes, improved HRQL and increased exercise capacity after two years in patients randomized to LVRS. Long-term (median 4.3 years) follow-up is now available from the NETT (346). The surgical arm showed a survival advantage with a five-year risk ratio for death of 0.86 $(\mathrm{P}=0.02)$ relative to medically treated patients. Improvements in maximal exercise and HRQL were maintained for three and four years, respectively. As in the twoyear results, patients with upper lobe-predominant emphysema and low exercise capacity (less than $40 \mathrm{~W}$ ) had the best results, with a five-year risk ratio for death of 0.67
$(\mathrm{P}=0.003)$. Upper lobe-predominant emphysema with high exercise capacity had no survival advantage but did show sustained improvements in exercise capacity and HRQL.

The Panel considers this new information to be supportive of LVRS as a potentially effective option for management of advanced COPD (level of evidence: 1A) in patients who meet the carefully designed criteria defined by these studies (Table 11). However, the procedure is expensive, with estimates of $\$ 120,000$ per quality-adjusted life year gained $(343,347)$, and its adoption should be balanced against the available resources. Recent innovations that use the knowledge gained from LVRS, such as bronchial lung volume reduction (348), may well be more cost-effective but an RCT is required before any recommendation can be made.

\section{Lung transplantation for COPD}

Lung transplantation is an excellent option for certain carefully selected patients with advanced COPD (level of evidence: 3A). Over 12,000 lung transplants have been performed to date, with COPD accounting for $60 \%$ and $30 \%$ of the single and bilateral procedures, respectively (349). Anticipated survival rates following lung transplantation for all disease states are in the range of $75 \%$ at one year and $50 \%$ at five years (349). However, recipients with COPD appear to have better outcomes than those with other conditions (level of evidence: 3B). Chronic graft dysfunction associated with obliterative bronchiolitis, thought to be a manifestation of chronic rejection, is the major complication affecting long-term morbidity and mortality, and is present in at least one-half of long-term survivors (350). The latest guidelines from the International Society for Heart and Lung Transplantation suggest that patients with COPD should be referred when they have a BODE score of five (351).

\section{Recommendation}

- Patients with COPD are considered to be potentially in the transplant window if they meet at least one of the following criteria: $\mathrm{FEV}_{1}$ less than $25 \%$ predicted (without reversibility), partial pressure of arterial carbon dioxide greater than $55 \mathrm{mmHg}$ or elevated pulmonary artery pressures with progressive deterioration (eg, cor pulmonale) (level of evidence: 3B). 


\section{AAT DEFICIENCY}

The CTS has published detailed guidelines on the assessment and management of AAT deficiency (352).

\section{Recommendation}

- The Panel recommends restricting the option for AAT replacement therapy to AAT-deficient patients with an $\mathrm{FEV}_{1}$ greater than $35 \%$ and less than $65 \%$ predicted who have quit smoking and are on optimal medical therapy yet continue to show a rapid decline in $\mathrm{FEV}_{1}$ (greater than $80 \mathrm{~mL} /$ year or greater) (353) (level of evidence: 2C).

\section{END-OF-LIFE ISSUES IN COPD}

The Panel believes that we need to improve our understanding of patients' experiences and needs through well-timed, honest, informative and empathetic, yet realistic, conversations that can form the basis of effective advanced care planning. Discussions about end-of-life issues often occur too late, are held in inappropriate settings (such as the ICU) and do not meet the expectations of patients (354). Patients with features of advanced disease that increase the likelihood of death from an episode of acute exacerbation should be targeted for discussions regarding end-of-life care preferences during outpatient visits. These features of advanced disease can be summarized in a global score (eg, the BODE index [108]) or identified individually as severe airflow obstruction (eg, $\mathrm{FEV}_{1}$ less than $40 \%$ predicted), poor functional status (eg, MRC 4 to 5), poor nutritional status (eg, body mass index less than $19 \mathrm{~kg} / \mathrm{m}^{2}$ ) and recurrent severe acute exacerbations requiring hospitalization (355,356).

The quality of life of patients with advanced COPD is often poor. Many patients with advanced COPD rate their quality of life as worse than that of patients who have survived cardiopulmonary resuscitation or living with inoperable lung cancer $(357,358)$. The emotional consequences of severe COPD include anxiety, fear, panic and depression. These psychological factors can impose an additional barrier to effective symptom control $(359,360)$, further reduce quality of life and require pharmacological and nonpharmacological treatment strategies for effective management.

Caregiver burden is a major concern to patients with advanced COPD (361). Few studies have adequately evaluated this aspect of the disease, partly due to a lack of validated instruments to measure caregiver burden in COPD.

\section{Symptom control}

- It is reasonable to optimize and maximize bronchodilator therapy in dyspneic patients in the final phases of their illness.

- The role of oxygen in the palliation of dyspnea in mildly hypoxic, advanced COPD has not been adequately investigated. Without further study, the routine use of oxygen for dyspnea palliation in COPD patients without severe hypoxia cannot be justified.

- Opioids remain the most effective dyspnea-relieving medications in end-of-life care (Table 12).
TABLE 12

Agents used to manage symptoms related to chronic obstructive pulmonary disease at the end of life

\begin{tabular}{|c|c|c|}
\hline Indication & Drug & Commonly used dosage \\
\hline \multirow[t]{14}{*}{ Dyspnea } & Morphine & \\
\hline & Oral & $5 \mathrm{mg}$ to $10 \mathrm{mg} \mathrm{q} 4 \mathrm{~h}$ \\
\hline & Per rectum & $5 \mathrm{mg}$ to $10 \mathrm{mg} \mathrm{q} 4 \mathrm{~h}$ \\
\hline & IV, SC or IM & Titrate to relieve dyspnea \\
\hline & Nebulized & $\begin{array}{l}5 \mathrm{mg} \text { in } 2 \mathrm{~mL} \text { normal saline } \\
\mathrm{q} 4 \mathrm{~h} \text { with hand-held nebulizer }\end{array}$ \\
\hline & Benzodiazepines & \\
\hline & $\begin{array}{l}\text { Lorazepam, oral, } \\
\text { sublingual, IV }\end{array}$ & $1 \mathrm{mg}$ to $2 \mathrm{mg} \mathrm{q} 1-4 \mathrm{~h}$ \\
\hline & Diazepam, oral, IV & $2.5 \mathrm{mg}$ to $25 \mathrm{mg}$ daily \\
\hline & Midazolam, SC & $5 \mathrm{mg}$ to $10 \mathrm{mg} \mathrm{SC}$, then \\
\hline & & $10 \mathrm{mg}$ to $30 \mathrm{mg}$ continuous \\
\hline & & $\mathrm{SC}$ infusion for two days \\
\hline & Other & \\
\hline & Chlorpromazine, IV & $12.5 \mathrm{mg}$ IV q4-6h \\
\hline & Chlorpromazine, per rectum & $25 \mathrm{mg} \mathrm{q4-6h}$ \\
\hline \multirow[t]{5}{*}{ Cough } & Opioids & \\
\hline & Codeine, oral & $30 \mathrm{mg}$ to $60 \mathrm{mg} \mathrm{q} 4 \mathrm{~h}$ \\
\hline & Morphine, IV & $2.5 \mathrm{mg}$ to $5 \mathrm{mg} \mathrm{q} 4 \mathrm{~h}$ \\
\hline & Inhaled anesthetics & \\
\hline & Bupivacaine, $0.25 \%$ & $5 \mathrm{mg}$ q4-6h \\
\hline \multirow{5}{*}{$\begin{array}{l}\text { Retained } \\
\text { secretions }\end{array}$} & Anticholinergic agents & \\
\hline & Scopolamine, SC & $0.4 \mathrm{mg}$ to $0.6 \mathrm{mg} \mathrm{q4-6h}$ \\
\hline & $\begin{array}{l}\text { Scopolamine, } \\
\text { transdermal patch }\end{array}$ & $1.5 \mathrm{mg} \mathrm{q} 72 \mathrm{~h}$ \\
\hline & Hyoscyamine, SC & $0.25 \mathrm{mg}$ to $0.5 \mathrm{mg} \mathrm{q} 4-6 \mathrm{~h}$ \\
\hline & Atropine, SC & $0.4 \mathrm{mg}$ q4-6h \\
\hline
\end{tabular}

IM Intramuscular; IV Intravenous; q Every; SC Subcutaneous

- Noninvasive ventilation may be effective (with likely reversible causes of acute respiratory failure) and may also provide some symptom relief in COPD patients who otherwise would not accept intubation and mechanical ventilation (326). However, further studies are required to establish the role of noninvasive ventilation in the palliative care setting.

\section{Recommendations}

- COPD patients should be encouraged to articulate to their physicians and caregivers a desire for information about their disease, prognosis and the possible circumstances of their death (level of evidence: 2A).

- COPD patients who are at an increased risk of dying in the near future should benefit most from timely discussions about end-of-life issues (level of evidence: 2A).

For information on the CTS COPD Guidelines Dissemination and Implementation Committee, or to request COPD Guideline Implementation tools, please visit our Web site at $<$ www.COPDguidelines.ca $>$. 
ACKNOWLEDGEMENTS: The authors wish to thank Canadian Lung Association administrative staff Laura Monette and Virginia Fobert for their assistance with the manuscript. Reviewers of the manuscript include: Michelle Bishop (Centre for Chronic Disease Prevention and Control, Public Health Agency of Canada), Elaine Chong (Canadian Pharmacists Association), Gordon Dyck (Family Physician), Darrel Melvin (Respiratory Health Services), Pat Steele (Canadian Respiratory Health Professionals), Cheryl Winger (Canadian Respiratory Health Professionals), Susan Deveau, Brad Donoff, Jennifer Haddon, Martin Holroyde, Nicholas Makris, Renata Rea, Carle Rykman, Kevin Schultz, Michael Shaw and Katherine Webb.

SPONSORING ORGANIZATIONS: Canadian College of Family Physicians, The Lung Association, Canadian Respiratory Health Professionals.

COMPETING INTERESTS: Collectively, the physicians on the Scientific Review Panel have on at least one occasion 1) acted as consultants for; 2) received research funds from; 3 ) received speaker's fees from; and 4) received travel assistance from the various pharmaceutical companies listed below.

FUNDING: These guidelines were developed under the auspices of the Scientific Review Panel of the Canadian Thoracic Society. This process was facilitated by funding from Abbot Laboratories Inc, ALTANA Pharma Inc, AstraZeneca Canada Inc, Bayer Canada Inc, Boehringer Ingelheim (Canada) Inc, GlaxoSmithKline Inc and Pfizer Canada. None of the pharmaceutical sponsors played a role in the collection, review, analysis or interpretation of the scientific data or in any decisions regarding recommendations.

\section{REFERENCES}

1. Ernst P, Fitzgerald J, Spier S. Canadian Asthma Consensus Conference: Summary of recommendations. Can Respir J 1996;3:89-100.

2. Pellegrino R, Viegi G, Brusasco V, et al. Interpretative strategies for lung function tests. Eur Respir J 2005;26:948-68.

3. Deaths by selected grouped causes, sex and geography - Canada. <www.statcan.ca/english/freepub/84F0209XIE/2003000/t001_en.pdf> (Version current at July 18, 2007).

4. Respiratory Disease in Canada. www.phac-aspc.gc.ca/publicat/rdcmrc01/pdf/rdc0901e.pdf (Version current at July 18, 2007).

5. Ernst PP, Bourbeau J, Rainville B, Benayoun S, Suissa S. Underestimation of COPD as a cause of death. Eur Respir J 2000;16(Suppl 31):13S.

6. Shahab L, Jarvis MJ, Britton J, West R. Prevalence, diagnosis and relation to tobacco dependence of chronic obstructive pulmonary disease in a nationally representative population sample. Thorax 2006;61:1043-7.

7. Dales RE, Vandemheen KL, Clinch J, Aaron SD. Spirometry in the primary care setting: Influence on clinical diagnosis and management of airflow obstruction. Chest 2005;128:2443-7.

8. Celli BR, MacNee W, ATS/ERS Task Force. Standards for the diagnosis and treatment of patients with COPD: A summary of the ATS/ERS position paper. Eur Respir J 2004;23:932-46.

9. Siafakas NM. Definition and differential diagnosis of chronic obstructive pulmonary disease. Eur Respir Mon 2006;38:1-6.

10. Mullen JB, Wright JL, Wiggs BR, Pare PD, Hogg JC. Reassessment of inflammation of airways in chronic bronchitis. Br Med J (Clin Res Ed) 1985;291:1235-9.

11. Cosio M, Ghezzo H, Hogg JC, et al. The relations between structural changes in small airways and pulmonary-function tests. N Engl J Med 1978;298:1277-81.

12. Niewoehner DE, Kleinerman J, Rice DB. Pathologic changes in the peripheral airways of young cigarette smokers. N Engl J Med 1974;291:755-8

13. Wright JL, Lawson LM, Pare PD, Wiggs BJ, Kennedy S, Hogg JC. Morphology of peripheral airways in current smokers and ex-smokers. Am Rev Respir Dis 1983;127:474-7.
14. Ollerenshaw SL, Woolcock AJ. Characteristics of the inflammation in biopsies from large airways of subjects with asthma and subjects with chronic airflow limitation. Am Rev Respir Dis 1992;145:922-7.

15. Hunninghake GW, Crystal RG. Cigarette smoking and lung destruction. Accumulation of neutrophils in the lungs of cigarette smokers. Am Rev Respir Dis 1983;128:833-8.

16. O'Shaughnessy TC, Ansari TW, Barnes NC, Jeffrey PK. Inflammation in bronchial biopsies of subjects with chronic bronchitis: Inverse relationship of CD8+ T lymphocytes with $\mathrm{FEV}_{1}$. Am J Respir Crit Care Med 1997;155:852-7.

17. Saetta M, DiStefano A, Maestrelli P, et al. Activated T-lymphocytes and macrophages in bronchial mucosa of subjects with chronic bronchitis. Am Rev Respir Dis 1993;147:301-6.

18. Saetta M, Di Stefano A, Turato G, et al. CD8+ T-lymphocytes in peripheral airways of smokers with chronic obstructive pulmonary disease. Am J Respir Crit Care Med 1998;157:822-6.

19. Leopold JG, Gough J. The centrilobular form of hypertrophic emphysema and its relation to chronic bronchitis. Thorax 1957;12:219-35.

20. McLean KH. Pathogenesis of pulmonary emphysema. Am J Med 1958;25:62-74

21. Repine JE, Bast A, Lankhorst I. Oxidative stress in chronic obstructive pulmonary disease. Oxidative Stress Study Group. Am J Respir Crit Care Med 1997;156:341-57.

22. Shapiro SD. End-stage chronic obstructive pulmonary disease: The cigarette is burned out but inflammation rages on. Am J Respir Crit Care Med 2001;164:339-40.

23. Hogg JC, Chu F, Utokaparch S, et al. The nature of small-airway obstruction in chronic obstructive pulmonary disease. N Engl J Med 2004;350:2645-53

24. Fabbri LM, Romagnoli M, Corbetta L, et al. Differences in airway inflammation in patients with fixed airflow obstruction due to asthma or chronic obstructive pulmonary disease. Am J Respir Crit Care Med 2003;167:418-24.

25. O'Donnell DE, Webb KA. Exertional breathlessness in patients with CAL: The role of lung hyperinflation. Am Rev Respir Dis 1993;48:1351-57.

26. O'Donnell DE, Revill S, Webb KA. Dynamic hyperinflation and exercise intolerance in COPD. Am J Respir Crit Care Med 2001; 164:770-7.

27. Tantucci C, Duguet A, Similowski T, Zelter M, Derenne JP, Milic-Emili J. Effect of salbutamol on dynamic hyperinflation in chronic obstructive pulmonary disease patients. Eur Respir J 1998; 12:799-804.

28. Parker CM, Voduc N, Aaron SD, Webb KA, O'Donnell DE. Physiological changes during symptom recovery from moderate exacerbations of COPD. Eur Respir J 2005;26:420-8.

29. Stevenson NJ, Walker PP, Costello RW, Calverley PM. Lung mechanics and dyspnea during exacerbations of chronic obstructive pulmonary disease. Am J Respir Crit Care Med 2005;172:1510-6.

30. MacNee W. Pathophysiology of cor pulmonale in chronic obstructive pulmonary disease. Part two. Am J Respir Crit Care Med 1994;150:1158-68.

31. Barbera JA, Peinado VI, Santos S. Pulmonary hypertension in chronic obstructive pulmonary disease. Eur Respir J 2003;21:892-905

32. Wright JL, Levy RD, Churg A. Pulmonary hypertension in chronic obstructive pulmonary disease: Current theories of pathogenesis and their implications for treatment. Thorax 2005;60:605-9.

33. Weitzenblum E, Hirth C, Ducolone A, Mirhom R, Rasaholinjanahary J, Ehrhart M. Prognostic value of pulmonary artery pressure in chronic obstructive pulmonary disease. Thorax 1981;36:752-8

34. Bishop JM, Cross KW. Physiological variables and mortality in patients with various categories of chronic respiratory disease. Bull Eur Physiopathol Respir 1984;20:495-500.

35. Chaouat A, Bugnet A-S, Kadaoui N, et al. Severe pulmonary hypertension and chronic obstructive pulmonary disease. Am J Respir Crit Care Med 2005;172:189-94.

36. Calverley PM, Anderson JA, Celli B, et al. Salmeterol and fluticasone propionate and survival in chronic obstructive pulmonary disease. N Engl J Med 2007;356:775-89.

37. Sin DD, Man JP, Man SF. The risk of osteoporosis in Caucasian men and women with obstructive airways disease. Am J Med 2003;114:10-4 
38. Soriano JB, Visick GT, Muellerova H, Payvandi N, Hansell AL. Patterns of comorbidities in newly diagnosed COPD and asthma in primary care. Chest 2005;128:2099-107.

39. Wouters EF. Chronic obstructive pulmonary disease. 5: Systemic effects of COPD. Thorax 2002;57:1067-70.

40. Broekhuizen R, Wouters EF, Creutzberg EC, Schols AM. Raised CRP levels mark metabolic and functional impairment in advanced COPD. Thorax 2006;61:17-22.

41. Man SF, Connett JE, Anthonisen NR, Wise RA, Tashkin DP, Sin DD. C-reactive protein and mortality in mild to moderate chronic obstructive pulmonary disease. Thorax 2006;61:849-53.

42. Sin DD, Anthonisen NR, Soriano JB, Agusti AG. Mortality in COPD: Role of comorbidities. Eur Respir J 2006;28:1245-57.

43. Yohannes AM. Depression and COPD in older people: A review and discussion. Br J Community Nurs 2005;10:42-6.

44. Breslin E, van der Schans C, Breukink S, et al. Perception of fatigue and quality of life in patients with COPD. Chest 1998;114:958-64.

45. Sidney S, Sorel M, Quesenberry CP Jr, DeLuise C, Lanes S, Eisner MD. COPD and incident cardiovascular disease hospitalizations and mortality: Kaiser Permanente Medical Care Program. Chest 2005;128:2068-75.

46. Anthonisen NR, Connett JE, Enright PL, Manfreda J. Hospitalizations and mortality in the Lung Health Study. Am J Respir Crit Care Med 2002;166:333-9.

47. Antonelli Incalzi R, Fuso L, De Rosa M, et al. Co-morbidity contributes to predict mortality of patients with chronic obstructive pulmonary disease. Eur Respir J 1997;10:2794-800.

48. Jagoe RT, Engelen MP. Muscle wasting and changes in muscle protein metabolism in chronic obstructive pulmonary disease. Eur Respir J 2003;22(Suppl 46):52S-63S.

49. Schols AM, Mostert R, Soeters PB, Wouters EF. Body composition and exercise performance in patients with chronic obstructive pulmonary disease. Thorax 1991;46:695-9.

50. Hughes RL, Katz H, Sahgal V, Campbell JA, Hartz R, Shields TW. Fiber size and energy metabolites in five separate muscles from patients with chronic obstructive lung diseases. Respiration 1983;44:321-8

51. Satta A, Migliori GB, Spanevello A, et al. Fibre types in skeletal muscles of chronic obstructive pulmonary disease patients related to respiratory function and exercise tolerance. Eur Respir J 1997; 10:2853-60

52. Wilson DO, Rogers RM, Wright EC, Anthonisen NR. Body weight in chronic obstructive pulmonary disease. The National Institutes of Health Intermittent Positive-Pressure Breathing Trial. Am Rev Respir Dis 1989;139:1435-8.

53. Vestbo J, Prescott E, Almdal T, et al. Body mass, fat-free body mass, and prognosis in patients with chronic obstructive pulmonary disease from a random population sample: Findings from the Copenhagen City Heart Study. Am J Respir Crit Care Med 2006;173:79-83.

54. Sin DD, Man SF. Why are patients with chronic obstructive pulmonary disease at increased risk of cardiovascular diseases? The potential role of systemic inflammation in chronic obstructive pulmonary disease. Circulation 2003;107:1514-19.

55. Gan WQ, Man SF, Senthilselvan A, Sin DD. Association between chronic obstructive pulmonary disease and systemic inflammation: A systematic review and a meta-analysis. Thorax 2004:59:574-80.

56. Ross R. Atherosclerosis-an inflammatory disease. N Engl J Med 1999:340:115-26

57. Sin DD, Man SF. Skeletal muscle weakness, reduced exercise tolerance, and COPD: Is systemic inflammation the missing link? Thorax 2006;61:1-3.

58. Broekhuizen R, Grimble RF, Howell WM, et al. Pulmonary cachexia, systemic inflammatory profile, and the interleukin 1beta -511 single nucleotide polymorphism. Am J Clin Nutr 2005;82:1059-64

59. Rahman I, Morrison D, Donaldson K, MacNee W. Systemic oxidative stress in asthma, COPD, and smokers. Am J Respir Crit Care Med 1996;154:1055-60.

60. Couillard A, Maltais F, Saey D, et al. Exercise-induced quadriceps oxidative stress and peripheral muscle dysfunction in patients with chronic obstructive pulmonary disease. Am J Respir Crit Care Med 2003;167:1664-9.
61. Koechlin C, Maltais F, Saey D, et al. Hypoxaemia enhances peripheral muscle oxidative stress in chronic obstructive pulmonary disease. Thorax 2005;60:834-41

62. Calverley P, Bellamy D. The challenge of providing better care for patients with chronic obstructive pulmonary disease: The poor relation of airways obstruction? Thorax 2000;55:78-82.

63. Anthonisen NR, Connett JE, Murray RP. Smoking and lung function of Lung Health Study participants after 11 years. Am J Respir Crit Care Med 2002;166:675-9.

64. Anthonisen NR, Connett JE, Kiley JP, et al. Effects of smoking intervention and the use of an inhaled anticholinergic bronchodilator on the rate of decline of $\mathrm{FEV}_{1}$. The Lung Health Study. JAMA 1994;272:1497-505.

65. Walker PP, Mitchell P, Diamantea F, Warburton CJ, Davies L. Effect of primary-care spirometry on the diagnosis and management of COPD. Eur Respir J 2006;28:945-52.

66. Enright PL, Crapo RO. Controversies in the use of spirometry for early recognition and diagnosis of chronic obstructive pulmonary disease in cigarette smokers. Clin Chest Med 2000;21:645-52.

67. McIvor RA, Tashkin DP. Underdiagnosis of chronic obstructive pulmonary disease: A rationale for spirometry as a screening tool. Can Respir J 2001;8:153-8.

68. Eaton T, Withy S, Garrett JE, Mercer J, Whitlock RM, Rea HH. Spirometry in primary care practice: The importance of quality assurance and the impact of spirometry workshops. Chest 1999;116:416-23.

69. Hepper NG, Drage CW, Davies SF, et al. Chronic obstructive pulmonary disease: A community-oriented program including professional education and screening by a voluntary health agency. Am Rev Respir Dis 1980;121:97-104.

70. Hardie JA, Buist AS, Vollmer WM, Ellingsen I, Bakke PS, Mørkve O. Risk of over-diagnosis of COPD in asymptomatic elderly never-smokers. Eur Respir J 2002;20:1117-22.

71. ERS Task Force, Palange P, Ward SA, et al. Recommendations on the use of exercise testing in clinical practice. Eur Respir J 2007;29:185-209.

72. Fletcher CM, Elmes PC, Fairbairn AS, Wood CH. The significance of respiratory symptoms and the diagnosis of chronic bronchitis in a working population. Br Med J 1959;2:257-66.

73. Nishimura K, Izumi T, Tsukino M, Oga T. Dyspnea is a better predictor of 5-year survival than airway obstruction in patients with COPD. Chest 2002;121:1434-40.

74. Calverley PMA, Georgopoulos D. Chronic obstructive pulmonary disease: Symptoms and signs. Eur Respir Mon 2006;38:7-23.

75. Pinto-Plata VM, Cote C, Cabral H, Taylor J, Celli BR. The 6-min walk distance: Change over time and value as a predictor of survival in severe COPD. Eur Respir J 2004:23:28-33.

76. Casanova C, Cote CG, Marin JM, et al. The 6-min walking distance: Long-term follow up in patients with COPD. Eur Respir J 2007;29:535-40.

77. Gibson GJ, MacNee W. Chronic obstructive pulmonary disease: Investigations and assessment of severity. Eur Respir Mon 2006;38:24-40.

78. Oga T, Nishimura K, Tsukino M, Sato S, Hajiro T. Analysis of the factors related to mortality in chronic obstructive pulmonary disease: Role of exercise capacity and health status. Am J Respir Crit Care Med 2003;167:544-9.

79. O'Donnell D, Flüge T, Gerken F, et al. Effects of tiotropium on lung hyperinflation, dyspnoea and exercise tolerance in COPD. Eur Respir J 2004:23:832-40.

80. Maltais F, Hamilton A, Marciniuk D, et al. Improvements in symptom-limited exercise performance over $8 \mathrm{~h}$ with once-daily tiotropium in patients with COPD. Chest 2005;128:1168-78.

81. Roberts CM, Bugler JR, Melchor R, Hetzel MR, Spiro SG. Value of pulse oximetry in screening for long-term oxygen therapy requirement. Eur Respir J 1993;6:559-62.

82. Hargreave FE, Parameswaran K. Asthma, COPD and bronchitis are just components of airway disease. Eur Respir J 2006;28:264-7

83. Brightling CE, Monteiro W, Ward R, et al. Sputum eosinophilia and short-term response to prednisolone in chronic obstructive pulmonary disease: A randomised controlled trial. Lancet 2000;356:1480-5.

84. Leigh R, Pizzichini MM, Morris M, Maltais F, Hargreave FE, Pizzichini E. Stable COPD: Predicting benefit from high-dose inhaled corticosteroid treatment. Eur Respir J 2006;27:964-71 
85. Siva R, Green RH, Brightling CE, et al. Eosinophilic airway inflammation and exacerbations of COPD: A randomised controlled trial. Eur Respir J 2007;29:906-13.

86. Barnes PJ, Chowdhury B, Kharitonov SA, et al. Pulmonary biomarkers in chronic obstructive pulmonary disease. Am J Respir Crit Care Med 2006;174:6-14

87. Barnes PJ, Cosio MG. Cells and mediators of chronic obstructive pulmonary disease. Eur Respir Mon 2006;38:130-58.

88. Tzortzaki EG, Siafakas NM. Genetic susceptibility to chronic obstructive pulmonary disease. Eur Respir Mon 2006;38:84-99

89. Silverman EK. Progress in chronic obstructive pulmonary disease genetics. Proc Am Thorac Soc 2006;3:405-8.

90. Sandford AJ, Paré PD. Genetic risk factors for chronic obstructive pulmonary disease. Clin Chest Med 2000;21:633-43.

91. Donaldson GC, Seemungal TA, Bhowmik A, Wedzicha JA. Relationship between exacerbation frequency and lung function decline in chronic obstructive pulmonary disease. Thorax 2002;57:847-52.

92. Kanner RE, Anthonisen NR, Connett JE. Lower respiratory illnesses promote $\mathrm{FEV}(1)$ decline in current smokers but not ex-smokers with mild chronic obstructive pulmonary disease: Results from the lung health study. Am J Respir Crit Care Med 2001;164:358-64.

93. Wilkinson TM, Donaldson GC, Hurst JR, Seemungal TA, Wedzicha JA. Early therapy improves outcomes of exacerbations of chronic obstructive pulmonary disease. Am J Respir Crit Care Med 2004;169:1298-303.

94. Rodriguez-Roisin R. Toward a consensus definition for COPD exacerbations. Chest 2000;117(Suppl 2):398S-401S

95. Cao Z, Ong KC, Eng P, Tan WC, Ng TP. Frequent hospital readmissions for acute exacerbations of COPD and their associated factors. Respirology 2006;11:188-95.

96. Mushlin AI, Black ER, Connolly CA, Buonaccorso KM, Eberly SW. The necessary length of hospital stay for chronic pulmonary disease. JAMA 1991;266:80-3.

97. Connors AF, Dawson NV, Thomas C, et al. Outcomes following acute exacerbation of severe chronic obstructive lung disease. The SUPPORT investigators (Study to Understand Prognoses and Preferences for Outcomes and Risks of Treatments). Am J Respir Crit Care Med 1996;154:959-67.

98. Anthonisen NR, Wright EC, Hodgkin JE. Prognosis in chronic obstructive pulmonary disease. Am Rev Respir Dis 1986;133:14-20.

99. Schols AM, Slangen J, Volovics L, Wouters EF. Weight loss is a reversible factor in the prognosis of chronic obstructive pulmonary disease. Am J Respir Crit Care Med 1998;157:1791-7.

100. Groenewegen KH, Schols AM, Wouters EFM. Mortality and mortality-related factors after hospitalization for acute exacerbation of COPD. Chest 2003;124:459-67.

101. Naunheim KS, Wood DE, Krasna MJ, et al. Predictors of operative mortality and cardiopulmonary morbidity in the National Emphysema Treatment Trial. J Thorac Cardiovasc Surg 2006;131:43-53.

102. Landbo C, Prescott E, Lange P, Vestbo J, Almdal TP. Prognostic value of nutritional status in chronic obstructive pulmonary disease. Am J Respir Crit Care Med 1999;160:1856-61.

103. Dubois P, Jamart J, Machiels J, Smeets F, Lulling J. Prognosis of severely hypoxemic patients receiving long-term oxygen therapy. Chest 1994;105:469-74

104. Yohannes AM, Baldwin RC, Connolly M. Mortality predictors in disabling chronic obstructive pulmonary disease in old age. Age Ageing 2002;31:137-40

105. Casanova C, Cote C, de Torres JP, et al. Inspiratory-to-total lung capacity ratio predicts mortality in patients with chronic obstructive pulmonary disease. Am J Respir Crit Care Med 2005;171:591-7.

106. The COPD Committee Group of the Standards of Care Committee of the BTS. BTS guidelines for the management of chronic obstructive pulmonary disease. Thorax 1997;52(Suppl 5):S1-S28.

107. Rabe KF, Hurd S, Anzueto A. Global Strategy for the Diagnosis, Management, and Prevention of COPD - 2006 Update. Am J Respir Crit Care Med 2007. (Epub ahead of print)

108. Celli BR, Cote CG, Marin JM, et al. The body-mass index, airflow obstruction, dyspnea, and exercise capacity index in chronic obstructive pulmonary disease. New Engl J Med 2004;350:1005-12.
109. Ferrer M, Alonso J, Morera J, et al. Chronic obstructive pulmonary disease stage and health-related quality of life. The Quality of Life of Chronic Obstructive Pulmonary Disease Study Group. Ann Intern Med 1997;127:1072-9.

110. Calverley PMA, Pearson MG. Clinical and laboratory assessment. In: Macnee W, Pride N, Rennard S. Chronic obstructive pulmonary disease, 2nd edn. London: Arnold, 2003:282-309.

111. Chanez P, Vignola AM, O'Shaugnessy T, et al. Corticosteroid reversibility in COPD is related to features of asthma. Am J Respir Crit Care Med 1997;155:1529-34

112. Pizzichini E, Pizzichini MM, Gibson P, et al. Sputum eosinophilia predicts benefit from prednisone in smokers with chronic obstructive bronchitis. Am J Respir Crit Care Med 1998;158:1511-7.

113. Culpitt SV, Maziak W, Loukidis S, Nightingale JA, Matthews JL, Barnes PJ. Effect of high dose inhaled steroid on cells, cytokines, and proteases in induced sputum in chronic obstructive pulmonary disease. Am J Respir Crit Care Med 1999;160:1635-9.

114. Ries AL, Kaplan RM, Limberg TM, Prewitt LM. Effects of pulmonary rehabilitation on physiologic and psychosocial outcomes in patients with chronic obstructive pulmonary disease. Ann Intern Med 1995;122:823-32

115. Bourbeau J, Julien M, Maltais F, et al. Reduction of hospital utilization in patients with chronic obstructive pulmonary disease: A disease-specific self-management intervention. Arch Intern Med 2003;163:585-91.

116. Smoking and diabetes care: Results from the CCHS cycle 3.1 (2005). In: Your Community, Your Health: Findings from the Canadian Community Health Survey (CCHS), 2006. Ottawa, Canada: Statistics Canada, 2006.

117. Lundbäck B, Lindberg A, Lindström M, et al. Not 15 but $50 \%$ of smokers develop COPD? - Report from the Obstructive Lung Disease in Northern Sweden Studies. Respir Med 2003;97:115-22

118. Centers for Disease Control and Prevention. Cigarette smoking among adults - United States, 2002. MMWR Morb Mortal Wkly Rep 2004;53:427-31.

119. Fiore MC. Treating tobacco use and dependence. $<$ www.surgeongeneral.gov/tobacco/treating_tobacco_use.pdf > (Version current at July 20, 2007).

120. van der Meer RM, Wagena EJ, Ostelo RW, Jacobs JE, van Schayck CP Smoking cessation for chronic obstructive pulmonary disease (Cochrane Review). In: The Cochrane Library, Issue 2, 2003. Chichester, UK: John Wiley \& Sons, Ltd, 2003.

121. Jorenby DE, Hays JT, Rigotti NA, et al. Efficacy of varenicline, an alpha4beta2 nicotinic acetylcholine receptor partial agonist, vs placebo or sustained-release bupropion for smoking cessation: A randomized controlled trial. JAMA 2006;296:56-63.

122. Gonzales D, Rennard SI, Nides M, et al. Varenicline, an alpha4beta2 nicotinic acetylcholine receptor partial agonist, vs sustained-release bupropion and placebo for smoking cessation: A randomized controlled trial. JAMA 2006;296:47-55.

123. Tonstad S, Tønnesen P, Hajek P, et al. Effect of maintenance therapy with varenicline on smoking cessation: A randomized controlled trial. JAMA 2006;296:64-71.

124. Nides M, Oncken C, Gonzales D, et al. Smoking cessation with varenicline, a selective alpha4beta2 nicotinic receptor partial agonist: Results from a 7-week, randomized, placebo- and bupropion-controlled trial with 1-year follow-up. Arch Intern Med 2006;166:1561-8.

125. Oncken C, Gonzales D, Nides M, et al. Efficacy and safety of the novel selective nicotinic acetylcholine receptor partial agonist, varenicline, for smoking cessation. Arch Intern Med 2006; $166: 1571-7$

126. de Guia N. Rethinking Stop-Smoking Medications: Myths and facts. <www.oma.org/Health/tobacco/stopsmoke.asp> (Version current at July 20, 2007).

127. O'Donnell DE, Lam M, Webb KA. Measurement of symptoms, lung hyperinflation, and endurance during exercise in chronic obstructive pulmonary disease. Am J Respir Crit Care Med 1998; 158:1557-65.

128. Oga T, Nishimura K, Tsukino M, Hajiro T, Ideda A, Izumi T. The effects of oxitropium bromide on exercise performance in patients with stable chronic obstructive pulmonary disease. A comparison of three different exercise tests. Am J Resp Crit Care Med 2000;161:1897-901.

129. Higgins BG, Powell RM, Cooper S, Tattersfield AE. Effect of salbutamol and ipratropium bromide on airway calibre and 
bronchial reactivity in asthma and chronic bronchitis. Eur Respir J 1991;4:415-20.

130. Shah SS, Johnston D, Woodcock AA, Johnson M, Geddes DM. Breathlessness and exercise tolerance in chronic airflow obstruction: 2-hourly versus 4-hourly salbutamol by inhalation. Curr Med Res Opin 1983;8:345-9.

131. Jaeschke R, Guyatt GH, Willan A, et al. Effect of increasing doses of beta agonists on spirometric parameters, exercise capacity, and quality of life in patients with chronic airflow limitation. Thorax 1994:49:479-84.

132. Evald T, Keittelmann S, Sindrup JH, Lange P. The effect of inhaled terbutaline on $\mathrm{FEV}_{1}, \mathrm{FVC}$, dyspnoea and walking distance in patients with chronic obstructive lung disease. Respir Med 1992;86:93-6.

133. Hansen NC, May O. Domiciliary nebulized terbutaline in severe chronic airways obstruction. Eur Respir J 1990;3:463-4.

134. Guyatt GH, Townsend M, Pugsley SO, et al. Bronchodilators in chronic air-flow limitation. Effects on airway function, exercise capacity, and quality of life. Am Rev Respir Dis 1987; 135:1069-74

135. Ram FS, Sestini P. Regular inhaled short acting beta ${ }_{2}$ agonists for the management of stable chronic obstructive pulmonary disease: Cochrane systematic review and meta-analysis. Thorax 2003;58:580-4

136. In chronic obstructive pulmonary disease, a combination of ipratropium and albuterol is more effective than either agent alone. An 85-day multicenter trial. COMBIVENT Inhalation Aerosol Study Group. Chest 1994;105:1411-9.

137. Ikeda A, Nishimura K, Koyama H, Izumi T. Bronchodilating effects of combined therapy with clinical dosages of ipratropium bromide and salbutamol for stable COPD: Comparison with ipratropium bromide alone. Chest 1995;107:401-5.

138. Dahl R, Greefhorst LA, Nowak D, et al. Inhaled formoterol dry powder versus ipratropium bromide in chronic obstructive pulmonary disease. Am J Respir Crit Care Med 2001;164:778-84.

139. Ulrik CS. Efficacy of inhaled salmeterol in the management of smokers with chronic obstructive pulmonary disease: A single centre randomised, double blind, placebo controlled, crossover study. Thorax 1995;50:750-4.

140. Boyd G, Morice AH, Pounsford JC, Siebert M, Peslis N, Crawford C. An evaluation of salmeterol in the treatment of chronic obstructive pulmonary disease (COPD). Eur Respir J 1997;10:815-21.

141. Cazzola M, Matera MG, Santangelo G, Vinciguerra A, Rossi F, D'Amato G. Salmeterol and formoterol in partially reversible severe chronic obstructive pulmonary disease: A dose-response study. Respir Med 1995;89:357-62.

142. Grove A, Lipworth BJ, Reid P, et al. Effects of regular salmeterol on lung function and exercise capacity in patients with chronic obstructive airways disease. Thorax 1996;51:689-93.

143. Goldkorn A, Diotto P, Burgess C, et al. The pulmonary and extrapulmonary effects of high-dose formoterol in COPD: A comparison with salbutamol. Respirology 2004;9:102-8.

144. O'Donnell DE, Voduc N, Fitzpatrick M, Webb KA. Effect of salmeterol on the ventilatory response to exercise in COPD. Eur Respir J 2004;24:86-94.

145. O'Donnell DE, Sciurba F, Celli B, et al. Effect of fluticasone propionate/salmeterol on lung hyperinflation and exercise endurance in COPD. Chest 2006;130:647-56.

146. Casaburi R, Mahler DA, Jones PW, et al. A long-term evaluation of once-daily inhaled tiotropium in chronic obstructive pulmonary disease. Eur Respir J 2002;19:217-24.

147. Vincken W, van Noord JA, Greefhorst AP, et al. Improved health outcomes in patients with COPD during one year's treatment with tiotropium. Eur Respir J 2002;19:209-16.

148. O'Donnell DE, Flüge T, Gerken F, et al. Effects of tiotropium on lung hyperinflation, dyspnoea and exercise tolerance in COPD. Eur Respir J 2004;23:832-40.

149. Donohue JF, van Noord JA, Bateman ED, et al. A 6-month, placebo-controlled study comparing lung function and health status changes in COPD patients treated with tiotropium or salmeterol. Chest 2002;122:47-55

150. Dusser D, Bravo M-L, Iacono P. The effect of tiotropium on exacerbations and airflow in patients with COPD. Eur Respir J 2006;27:547-55.
151. Niewoehner DE, Rice K, Cote C, et al. Prevention of exacerbation of chronic obstructive pulmonary disease with tiotropium, a oncedaily inhaled anticholinergic bronchodilator: A randomized trial. Ann Intern Med 2005;143:317-26.

152. van Noord JA, Aumann J-L, Janssens E, et al. Comparison of tiotropium once daily, formoterol twice daily and both combined once daily in patients with COPD. Eur Respir J 2005;26:214-22.

153. Bateman ED, van Dyk M, Sagriotis A. Comparable spirometric efficacy of tiotropium compared with salmeterol plus fluticasone in patients with COPD: A pilot study. Pulm Pharmacol Ther 2006, Oct 13; doi:10.1016/j.pupt.2006.10.001.

154. Santus P, Centanni S, Verga M, Di Marco F, Matera MG, Cazzola M. Comparison of the acute effect of tiotropium versus a combination therapy with single inhaler budesonide/formoterol on the degree of resting pulmonary hyperinflation. Respir Med 2006;100:1277-81.

155. van Noord JA, Aumann JL, Janssens E, et al. Effects of tiotropium with and without formoterol on airflow obstruction and resting hyperinflation in patients with COPD. Chest 2006;129:509-17.

156. Aaron SD, Vandemheen KL, Fergusson D, et al. Tiotropium in combination with placebo, salmeterol, or fluticasone-salmeterol for treatment of chronic obstructive pulmonary disease: A randomized trial. Ann Intern Med 2007;146:545-55.

157. Murciano D, Auclair M-H, Pariente R, Aubier M. A randomized, controlled trial of theophylline in patients with severe chronic obstructive pulmonary disease. N Engl J Med 1989;320:1521-5.

158. Mahon JL, Laupacis A, Hodder RV, et al. Theophylline for irreversible chronic airflow limitation: A randomized study comparing $\mathrm{n}$ of 1 trial to standard practice. Chest 1999;115:38-48.

159. Mahler DA, Matthay RA, Snyder PE, Wells CK, Loke J. Sustained release theophylline reduces dyspnea in nonreversible obstructive airway disease. Am Rev Respir Dis 1985;131:22-5.

160. Dullinger D, Kronenberg R, Niewoehner DE. Efficacy of inhaled metaproterenol and orally-administered theophylline in patients with chronic airflow obstruction. Chest 1986;89:171-3.

161. Tsukino M, Nishimura K, Ikeda A, Hajiro T, Koyama H, Izumi T. Effects of theophylline and ipratropium bromide on exercise performance in patients with stable chronic obstructive pulmonary disease. Thorax 1998;53:269-73.

162. ZuWallack RL, Mahler DA, Reilly D, et al. Salmeterol plus theophylline combination therapy in the treatment of COPD. Chest 2001;119:1661-70.

163. Culpitt SV, Maziak W, Loukidis S, Nightingale JA, Matthews JL, Barnes PJ. Effect of high dose inhaled steroid on cells, cytokines, and proteases in induced sputum in chronic obstructive pulmonary disease. Am J Respir Crit Care Med 1999;160:1635-9.

164. Keatings VM, Jatakanon A, Worsdell YM, Barnes PJ. Effects of inhaled and oral glucocorticoids on inflammatory indices in asthma and COPD. Am J Respir Crit Care Med 1997;155:542-8.

165. Hattotuwa KL, Gizycki MJ, Ansari TW, Jeffery PK, Barnes NC. The effects of inhaled fluticasone on airway inflammation in chronic obstructive pulmonary disease: A double-blind, placebocontrolled biopsy study. Am J Respir Crit Care Med 2002;165:1592-6.

166. Gizycki MJ, Hattotuwa KL, Barnes N, Jeffery PK. Effects of fluticasone propionate on inflammatory cells in COPD: An ultrastructural examination of endobronchial biopsy tissue. Thorax 2002;57:799-803

167. Alsaeedi A, Sin DD, McAlister FA. The effects of inhaled corticosteroids in chronic obstructive pulmonary disease: A systematic review of randomized placebo-controlled trials. Am J Med 2002;113:59-65.

168. Paggiaro PL, Dahle R, Bakran I, Frith L, Hollingworth K, Efthimiou J. Multicentre randomised placebo-controlled trial of inhaled fluticasone propionate in patients with chronic obstructive pulmonary disease. International COPD Study Group. Lancet 1998;351:773-80.

169. Burge PS, Caverley PM, Jones PW, Spencer S, Anderson JA, Maslen TK. Randomised, double blind, placebo controlled study of fluticasone propionate in patients with moderate to severe chronic obstructive pulmonary disease: The ISOLDE trial. Br Med J (Clin Res Ed) 2000;320:1297-303.

170. Pauwels RA, Löfdahl CG, Laitinen LA, et al. Long-term treatment with inhaled budesonide in persons with mild chronic obstructive pulmonary disease who continue smoking. European Respiratory Society Study on Chronic Obstructive Pulmonary Disease. N Engl J Med 1999;340:1948-53. 
171. Vestbo J, Sørensen T, Lange P, Brix A, Torre P, Viskum K. Longterm effect of inhaled budesonide in mild and moderate chronic obstructive pulmonary disease: A randomized controlled trial. Lancet 1999;353:1819-23.

172. Lung Health Study Research Group. Effect of inhaled triamcinolone on the decline in pulmonary function in chronic obstructive pulmonary disease. N Engl J Med 2000;343:1902-9.

173. Suissa S. Observational studies of inhaled corticosteroids in chronic obstructive pulmonary disease: Misconstrued immortal time bias. Am J Respir Crit Care Med 2006;173:464.

174. Barnes NC, Qiu Y-S, Pavord ID, et al. Anti-inflammatory effects of salmeterol/fluticasone propionate in chronic obstructive lung disease. Am J Respir Crit Care Med 2006;173:736-43.

175. Bourbeau J, Christodoulopoulos P, Maltais F, Yamauchi Y, Olivenstein R, Hamid Q. Effect of salmeterol/fluticasone propionate on airway inflammation in COPD: A randomized controlled trial. Thorax 2007.

176. Hanania NA, Darken P, Horstman D, et al. The efficacy and safety of fluticasone propionate $(250 \mathrm{microg}) / \mathrm{salmeterol}(50 \mathrm{microg})$ combined in the Diskus inhaler for the treatment of COPD. Chest 2003;124:834-43

177. Nannini L, Cates CJ, Lasserson TJ, Poole P. Combined corticosteroid and long acting beta-agonist in one inhaler for chronic obstructive pulmonary disease (Cochrane Review). In: The Cochrane Library, Issue 3, 2004. Chichester, UK: John Wiley $\&$ Sons, Ltd

178. Kardos P, Wencker M, Glaab T, Vogelmeier C. Impact of salmeterol/fluticasone propionate versus salmeterol on exacerbation in severe chronic obstructive pulmonary disease. Am J Respir Crit Care Med 2007;175:144-9.

179. Disse B. Antimuscarinic treatment for lung diseases from research to clinical practice. Life Sci 2001;68:2557-64.

180. Toogood JH, Jennings B, Baskerville J, Anderson J, Johansson SA. Dosing regimen of budesonide and occurrence of oropharyngeal complications. Eur J Respir Dis 1984;65:35-44.

181. Toogood JH, Jennings B, Greenway RW, Chuang L. Candidiasis and dysphonia complicating beclomethasone treatment of asthma. J Allergy Clin Immunol 1980;65:145-53.

182. Williams AJ, Baghat MS, Stableforth DE, Cayton RM, Shenoi PM, Skinner C. Dysphonia caused by inhaled steroids: Recognition of a characteristic laryngeal abnormality. Thorax 1983;38:813-21.

183. Egan JJ, Maden C, Kalra S, Adams JE, Eastell R, Woodcock AA. A randomized, double-blind study comparing the effects of beclomethasone and fluticasone on bone density over two years. Eur Respir J 1999;13:1267-75.

184. Li JT, Ford LB, Chervinsky P, et al. Fluticasone propionate powder and lack of clinically significant effects on hypothalamic-pituitaryadrenal axis and bone mineral density over two years in adults with mild asthma. J Allergy Clin Immunol 1999;103:1062-8.

185. Garbe E, LeLorier J, Boivin JF, Suissa S. Inhaled and nasal glucocorticoids and the risks of ocular hypertension or open-angle glaucoma. JAMA 1997;277:722-7.

186. Garbe E, Suissa S, LeLorier J. Association of inhaled corticosteroid use with cataract extraction in elderly patients. JAMA 1998;280:539-43

187. Cumming RG, Mitchell P, Leeder SR. Use of inhaled corticosteroids and the risk of cataracts. N Engl J Med $1997 ; 337: 8-14$

188. Ernst P, Gonzalez AV, Brassard P, Suissa S. Inhaled corticosteroid use in chronic obstructive pulmonary disease and the risk of hospitalization for pneumonia. Am J Respir Crit Care Med 2007;176:162-6.

189. Callahan CM, Dittus RS, Katz BP. Oral corticosteroid therapy for patients with stable chronic obstructive pulmonary disease. A metaanalysis. Ann Intern Med 1991;114:216-23.

190. Rice KL, Rubins JB, Lebahn F, et al. Withdrawal of chronic systemic corticosteroids in patients with COPD: A randomized trial. Am J Respir Crit Care Med 2000;162:174-8.

191. David DS, Grieco MH, Cushman P. Adrenal glucocorticoids after twenty years. A review of their clinically relevant consequences. J Chron Dis 1970;22:637-711.

192. Lieberman P, Patterson R, Kunske R. Complications of long-term steroid therapy for asthma. J Allergy Clin Immunol 1972;49:329-36

193. McEvoy CE, Ensrud KE, Bender E, et al. Association between corticosteroid use and vertebral fractures in older men with chronic obstructive pulmonary disease. Am J Respir Crit Care Med 1998;157:704-9.

194. Decramer M, Lacquet LM, Fagard R, Rogiers P. Corticosteroids contribute to muscle weakness in chronic airflow obstruction. Am J Respir Crit Care Med 1994:150:11-6.

195. Biskobing DM. COPD and osteoporosis. Chest 2002;121:609-20.

196. Burrows B, Earle RH. Course and prognosis of chronic obstructive lung disease. A prospective study of 200 patients. N Engl J Med 1969;280:397-404

197. Seemungal TA, Donaldson GC, Paul EA, Bestall JC, Jeffries DJ, Wedzicha JA. Effect of exacerbation on quality of life in patients with chronic obstructive pulmonary disease. Am J Respir Crit Care Med 1998;157:1418-22.

198. Niewoehner DE. The impact of severe exacerbations on quality of life and the clinical course of chronic obstructive pulmonary disease. Am J Med 2006;119(Suppl 1):38-45.

199. Kanner RE, Anthonisen NR, Connett JE; Lung Health Study Research Group. Lower respiratory illnesses promote FEV(1) decline in current smokers but not ex-smokers with mild chronic obstructive pulmonary disease: Results from the lung health study. Am J Respir Crit Care Med 2001;164:358-64.

200. Wilkinson TM, Donaldson GC, Hurst JR, Seemungal TA, Wedzicha JA. Early therapy improves outcomes of exacerbations of chronic obstructive pulmonary disease. Am J Respir Crit Care Med 2004;169:1298-303.

201. Cao Z, Ong KC, Eng P, Tan WC, Ng TP. Frequent hospital readmissions for acute exacerbation of COPD and their associated factors. Respirology 2006;11:188-95.

202. Mushlin AI, Black ER, Connolly CA, Buonaccorso KM, Eberly SW. The necessary length of hospital stay for chronic pulmonary disease. JAMA 1991;266:80-3.

203. Connors AF, Dawson NV, Thomas C, et al. Outcomes following acute exacerbation of severe chronic obstructive lung disease. The SUPPORT investigators (Study to Understand Prognoses and Preferences for Outcomes and Risks of Treatments). Am J Respir Crit Care Med 1996;154:959-67.

204. Burk RH, George RB. Acute respiratory failure in chronic obstructive pulmonary disease. Immediate and long-term prognosis. Arch Intern Med 1973;132:865-8.

205. Portier F, Defouilloy C, Muir JF. Determinants of immediate survival among chronic respiratory insufficiency patients admitted to an intensive care unit for acute respiratory failure. A prospective multicenter study. The French Task Group for Acute Respiratory Failure in Chronic Respiratory Insufficiency. Chest 1992;101:204-10.

206. Seneff MG, Wagner DP, Wagner RP, Zimmerman JE, Knaus WA. Hospital and one-year survival of patients admitted to intensive care units with acute exacerbation of chronic obstructive pulmonary disease. JAMA 1995;274:1852-7.

207. Cydulka RK, McFadden ER Jr, Emerman CL, Sivinski LD, Pisanelli W, Rimm AA. Patterns of hospitalization in elderly patients with asthma and chronic obstructive pulmonary disease. Am J Respir Crit Care Med 1997;156:1807-12.

208. Osman IM, Godden DJ, Friend JA, Legge JS, Douglas JG. Quality of life and hospital re-admission in patients with chronic obstructive pulmonary disease. Thorax 1997;52:67-71.

209. Tillie-Leblond I, Marquette CH, Perez T, et al. Pulmonary embolism in patients with unexplained exacerbation of chronic obstructive pulmonary disease: Prevalence and risk factors. Ann Intern Med 2006;144:390-6.

210. Simmons MS, Connett JE, Nides MA, et al. Smoking reduction and the rate of decline in FEV(1): Results from the Lung Health Study. Eur Respir J 2005;25:1011-7.

211. Nichol K, Baken L, Nelson A. Relation between influenza vaccination and outpatient visits, hospitalizations and mortality among elderly patients with chronic lung disease. Ann Intern Med 1999; 130:397-403

212. Wongsurakiat P, Maranetra KN, Wasi C, Kositanont U, Dejsomritrutai W, Charoenratanakul S. Acute respiratory illness in patients with COPD and the effectiveness of influenza vaccination: A randomized controlled study. Chest 2004;125: 2011-20.

213. Butler JC, Breiman RF, Campbell JF, Lipman HB, Broome CV, Facklam RR. Pneumococcal polysaccharide vaccine efficacy. An evaluation of current recommendations. JAMA 1993;270:1826-31.

214. Alfageme I, Vazquez R, Reyes N, et al. Clinical efficacy of antipneumococcal vaccination in patients with COPD. Thorax 2006;61:189-95 
215. Casas A, Troosters T, Garcia-Aymerich J, et al. Integrated care prevents hospitalisations for exacerbations in COPD patients. Eur Respir J 2006;28:123-30.

216. Gallefoss F, Bakke PS. Cost-benefit and cost-effectiveness analysis of self-management in patients with COPD - a one-year follow-up randomized, controlled trial. Respir Med 2002;96:424-31.

217. Bourbeau J, Collet JP, Schwartzman K, Ducruet T, Nault D, Bradley C. Economic benefits of self-management education in COPD. Chest 2006;130:1704-11.

218. Rossi A, Kristufek P, Levine BE, et al. Comparison of the efficacy, tolerability, and safety of formoterol dry powder and oral, slow release theophylline in the treatment of COPD. Chest 2002;121:1058-69.

219. Calverley P, Pauwels R, Vestbo J, et al. Combined salmeterol and fluticasone in the treatment of chronic obstructive pulmonary disease: A randomised controlled trial. Lancet 2003;361:449-56.

220. Brusasco V, Hodder R, Miravitlles M, Korducki L, Towse L, Kesten S. Health outcomes following treatment for six months with once daily tiotropium compared with twice daily salmeterol in patients with COPD. Thorax 2003;58:399-404

221. Barr RG, Bourbeau J, Camargo CA, Ram FS. Tiotropium for stable chronic obstructive pulmonary disease: A meta-analysis. Thorax 2006;61:854-62.

222. van der Valk P, Monninkhof E, van der Palen J, Zielhuis G, van Herwaarden C. Effect of discontinuation of inhaled corticosteroids in patients with chronic obstructive pulmonary disease: The COPE study. Am J Respir Crit Care Med 2002;166:1358-63.

223. Calverley PM, Boonsawat W, Cseke Z, Zhong N, Peterson S, Olsson H. Maintenance therapy with budesonide and formoterol in chronic obstructive pulmonary disease. Eur Respir J 2003;22:912-9.

224. Szafranski W, Cukier A, Ramirez A, et al. Efficacy and safety of budesonide/formoterol in the management of chronic obstructive pulmonary disease. Eur Respir J 2003;21:74-81.

225. Wouters EF, Postma DS, Fokkens B, et al. Withdrawal of fluticasone propionate from combined salmeterol/fluticasone treatment in patients with COPD causes immediate and sustained disease deterioration: A randomised controlled trial. Thorax 2005;60:480-7.

226. Jones PW, Willits LR, Burge PS, Calverley PM, Inhaled Steroids in Obstructive Lung Disease in Europe study investigators. Disease severity and the effect of fluticasone propionate on chronic obstructive pulmonary disease exacerbations. Eur Respir J 2003;21:68-73.

227. Suissa S. Statistical treatment of exacerbations in therapeutic trials of chronic obstructive pulmonary disease. Am J Respir Crit Care Med 2006;173:842-6.

228. de Melo MN, Ernst P, Suissa S. Inhaled corticosteroids and the risk of a first exacerbation in COPD patients. Eur Respir J 2004;23:692-97.

229. Aaron SD, Vandemheen KL, Hebert P, et al. Outpatient oral prednisone after emergency treatment of chronic obstructive pulmonary disease. N Engl J Med 2003;348:2618-25.

230. Griffiths TL, Burr ML, Campbell IA, et al. Results at one year of outpatient multidisciplinary pulmonary rehabilitation: A randomized controlled trial. Lancet 2000;355:362-8.

231. Güell R, Casan P, Belda J, et al. Long-term effects of outpatient rehabilitation of COPD: A randomized trial. Chest 2000;117:976-83

232. Troosters T, Gosselink R, Decramer M. Short-and long-term effects of outpatient rehabilitation in patients with chronic obstructive pulmonary disease: A randomized trial. Am J Med 2000;109:207-12.

233. California Pulmonary Rehabilitation Collaborative Group. Effects of pulmonary rehabilitation on dyspnea, quality of life, and healthcare costs in California. J Cardiopulm Rehabil 2004;24:52-62.

234. Hui KP, Hewitt AB. A simple pulmonary rehabilitation program improves health outcomes and reduces hospital utilization in patients with COPD. Chest 2003;124:94-7.

235. Golmohammadi K, Jacobs P, Sin DD. Economic evaluation of a community-based pulmonary rehabilitation program for COPD. Lung 2004;182:187-96.

236. Tillie-Leblond I, Marquette $\mathrm{CH}$, Perez T, et al. Pulmonary embolism in patients with unexplained exacerbation of chronic obstructive pulmonary disease: Prevalence and risk factors. Ann Intern Med 2006;144:390-6.
237. Emerman CL, Cydulka RK. Evaluation of high-yield criteria for chest radiography in acute exacerbation of chronic obstructive pulmonary disease. Ann Emerg Med 1993;22:680-4

238. Tsai TW, Gallagher EJ, Lombardi G, Gennis P, Carter W. Guidelines for the selective ordering of admission chest radiography in adult obstructive airway disease. Ann Emerg Med 1993;22:1854-8.

239. Karpel JP, Pesin J, Greenberg D, Gentry E. A comparison of the effects of ipratropium bromide and metaproterenol sulfate in acute exacerbations of COPD. Chest 1990;98:835-9.

240. Rebuck AS, Chapman KR, Abboud R, et al. Nebulized anticholinergic and sympathomimetic treatment of asthma and chronic obstructive airways disease in the emergency room. Am J Med 1987;82:59-64.

241. Zehner WJ Jr, Scott JM, Iannolo PM, Ungaro A, Terndrup TE. Terbutaline versus albuterol for out-of-hospital respiratory distress: Randomized, double-blind trial. Acad Emerg Med 1995;2:686-91.

242. Emerman CL, Cydulka RK. Effect of different albuterol dosing regimens in the treatment of acute exacerbation of chronic obstructive pulmonary disease. Ann Emerg Med 1997;29:474-8.

243. Di Marco F, Verga M, Santus P, Morelli N, Cazzola M, Centanni S. Effect of formoterol, tiotropium, and their combination in patients with acute exacerbation of chronic obstructive pulmonary disease: A pilot study. Respir Med 2006;100:1925-32.

244. Emerman CL, Connors AF, Lukens TW, May ME, Effron D, A randomized controlled trial of methylprednisolone in the emergency treatment of acute exacerbations of COPD. Chest 1989;95:563-7

245. Albert RK, Martin TR, Lewis SW. Controlled clinical trial of methylprednisolone in patients with chronic bronchitis and acute respiratory insufficiency. Ann Intern Med 1980;92:753-8.

246. Thompson WH, Nielson CP, Carvalho P, Charan NB, Crowley JJ. Controlled trial of oral prednisone in outpatients with acute COPD exacerbation. Am J Respir Crit Care Med 1996;154:407-12.

247. Davies L, Angus RM, Calverley PM. Oral corticosteroids in patients admitted to hospital with exacerbations of chronic obstructive pulmonary disease: A prospective randomized controlled trial. Lancet 1999;354:456-60.

248. Niewoehner DE, Erbland ML, Deupree RH, et al. Effect of systemic glucocorticoids on exacerbations of chronic obstructive pulmonary disease. Department of Veterans Affairs Cooperative Study Group. N Engl J Med 1999;340:1941-7.

249. Baker EH, Janaway CH, Philips BJ, et al. Hyperglycaemia is associated with poor outcomes in patients admitted to hospital with acute exacerbations of chronic obstructive pulmonary disease. Thorax 2006;61:284-9.

250. Anthonisen NR, Manfreda J, Warren CP, Hershfield ES, Harding GK, Nelson NA. Antibiotic therapy in exacerbations of chronic obstructive pulmonary disease. Ann Intern Med 1987;106:196-204.

251. Elmes PC, Fletcher CM, Dutton AA. Prophylactic use of oxytetracycline for exacerbations of chronic bronchitis. Br Med J 1957;2:1272-5

252. Berry DG, Fry J, Hindley CP, et al. Exacerbations of chronic bronchitis treatment with oxytetracycline. Lancet 1960;1:137-9.

253. Fear EC, Edwards G. Antibiotic regimes in chronic bronchitis. Br J Dis Chest 1962:56:153-62.

254. Elmes PC, King TK, Langlands JH, et al. Value of ampicillin in the hospital treatment of exacerbations of chronic bronchitis. Br Med J 1965;2:904-8.

255. Petersen ES, Esmann V, Honcke P, Munkner C. A controlled study of the effect of treatment on chronic bronchitis. An evaluation using pulmonary function tests. Acta Med Scand 1967;182:293-305.

256. Pines A, Raafat H, Plucinski K, Greenfield JS, Solari M. Antibiotic regimens in severe and acute purulent exacerbations of chronic bronchitis. Br Med J 1968;2:735-8.

257. Pines A, Raafat H, Greenfield JS, Linsell WD, Solari ME. Antibiotic regimens in moderately ill patients with purulent exacerbations of chronic bronchitis. Br J Dis Chest 1972;66:107-15.

258. Nicotra MB, Rivera M, Awe RJ. Antibiotic therapy of acute exacerbations of chronic bronchitis. A controlled study using tetracycline. Ann Intern Med 1982;97:18-21.

259. Saint S, Bent S, Vittinghoff E, Grady D. Antibiotics in chronic obstructive pulmonary disease exacerbations. A meta-analysis. JAMA 1995;273:957-60. 
260. Stockley RA, O'Brien C, Pye A, Hill SL. Relationship of sputum color to nature and outpatient management of acute exacerbations of COPD. Chest 2000;117:1638-45.

261. Stolz D, Christ-Crain M, Bingisser R, et al. Antibiotic treatment of exacerbations of COPD: A randomized, controlled trial comparing procalcitonin-guidance with standard therapy. Chest 2007;131:9-19.

262. Lacasse Y, Wong E, Guyatt GH, King D, Cook DJ, Goldstein RS. Meta-analysis of respiratory rehabilitation in chronic obstructive pulmonary disease. Lancet 1996;348:1115-9.

263. Lacasse Y, Goldstein R, Lasserson TJ, Martin S. Pulmonary rehabilitation for chronic obstructive pulmonary disease (Cochrane Review). In: The Cochrane Library, Issue 4, 2006. Chichester, UK: John Wiley \& Sons, Ltd.

264. Maltais F, LeBlanc P, Jobin J, et al. Intensity of training and physiologic adaptation in patients with chronic obstructive pulmonary disease. Am J Respir Crit Care Med 1997;155:555-61.

265. O'Donnell DE, McGuire M, Samis L, Webb KA. General exercise training improves ventilatory and peripheral muscle strength and endurance in chronic airflow limitation. Am J Respir Crit Care Med 1998;157:1489-97.

266. Nici L, Donner C, Wouters E, et al. American Thoracic Society/European Respiratory Society statement on pulmonary rehabilitation. Am J Respir Crit Care Med 2006;173:1390-413.

267. Simpson K, Killian K, McCartney N, Stubbing DG, Jones NL. Randomised controlled trial of weightlifting exercise in patients with chronic airflow limitation. Thorax 1992;47:70-5.

268. Clark CJ, Cochrane L, Mackay E. Low intensity peripheral muscle conditioning improves exercise tolerance and breathlessness in COPD. Eur Respir J 1996;9:2590-6.

269. Clark CJ, Cochrane LM, Mackay E, Paton B. Skeletal muscle strength and endurance in patients with mild COPD and the effects of weight training. Eur Respir J 2000;15:92-7.

270. Bernard S, Whittom F, Leblanc P, et al. Aerobic and strength training in patients with chronic obstructive pulmonary disease. Am J Respir Crit Care Med 1999;159:896-901.

271. Ortega F, Toral J, Cejudo P, et al. Comparison of effects of strength and endurance training in patients with chronic obstructive pulmonary disease. Am J Respir Crit Care Med 2002;166:669-74.

272. Mador MJ, Bozkanat E, Aggarwal A, Shaffer M, Kufel TJ. Endurance and strength training in patients with COPD. Chest 2004;125:2036-45

273. Spruit MA, Gosselink R, Troosters T, De Paepe K, Decramer M. Resistance versus endurance training in patients with COPD and peripheral muscle weakness. Eur Respir J 2002;19:1072-8.

274. Vogiatzis I, Terzis G, Nanas S, et al. Skeletal muscle adaptations to interval training in patients with advanced COPD. Chest 2005;128:3838-45.

275. Puhan MA, Büsching G, Schünemann HJ, VanOort E, Zaugg C, Frey M. Interval versus continuous high-intensity exercise in chronic obstructive pulmonary disease: A randomized trial. Ann Intern Med 2006;145:816-25.

276. Hawkins P, Johnson LC, Nikoletou D, et al. Proportional assist ventilation as an aid to exercise training in severe chronic obstructive pulmonary disease. Thorax 2002;57:853-9.

277. van't Hul A, Gosselink R, Hollander P, Postmus P, Kwakkel G. Training with inspiratory pressure support in patients with severe COPD. Eur Respir J 2006;27:65-72.

278. Emtner M, Porszasz J, Burns M, Somfay A, Casaburi R. Benefits of supplemental oxygen in exercise training in nonhypoxemic chronic obstructive pulmonary disease patients. Am J Respir Crit Care Med 2003; $168: 1034-42$

279. Nonoyama M, Brooks D, Lacasse Y, Guyatt G, Goldstein R. Oxygen therapy during exercise training in chronic obstructive pulmonary disease (Cochrane Review). In: The Cochrane Library, Issue 2, 2007. Chichester, UK: John Wiley \& Sons, Ltd.

280. Johnson JE, Gavin DJ, Adams-Dramiga S. Effects of training with heliox and noninvasive positive pressure ventilation on exercise ability in patients with severe COPD. Chest 2002;122:464-72.

281. Casaburi R, Bhasin S, Cosentino L, et al. Effects of testosterone and resistance training in men with chronic obstructive pulmonary disease. Am J Respir Crit Care Med 2004;170:870-8.

282. Bourjeily-Habr G, Rochester CL, Palermo F, Snyder P, Mohsenin V. Randomised controlled trial of transcutaneous electrical muscle stimulation of the lower extremities in patients with chronic obstructive pulmonary disease. Thorax 2002;57:1045-9.
283. Neder JA, Sword D, Ward SA, Mackay E, Cochrane LM, Clark CJ. Home based neuromuscular electrical stimulation as a new rehabilitative strategy for severely disabled patients with chronic obstructive pulmonary disease (COPD). Thorax 2002:57:333-7.

284. Vivodtzev I, Pépin JL, Vottero G, et al. Improvement in quadriceps strength and dyspnea in daily tasks after one month of electrical stimulation in severely deconditioned and malnourished COPD. Chest 2006;129:1540-8.

285. Dal Corso S, Nápolis L, Malaguti C, et al. Skeletal muscle structure and function in response to electrical stimulation in moderately impaired COPD patients. Respir Med 2007;101:1236-43.

286. Casaburi R, Patessio A, Ioli F, Zanaboni S, Donner CF, Wasserman K. Reductions in exercise lactic acidosis and ventilation as a result of exercise training in patients with obstructive lung disease. Am Rev Resp Dis 1991;143:9-18.

287. Puente-Maestu L, Sánz ML, Sánz P, Cubillo JM, Mayol J, Casaburi R. Comparison of effects of supervised versus selfmonitored training programmes in patients with chronic obstructive pulmonary disease. Eur Respir J 2000;15:517-25.

288. Puhan MA, Sharplatz M, Troosters T, Steurer J. Respiratory rehabilitation after acute exacerbation of COPD may reduce risk for readmission and mortality - a systematic review. Respir Res 2005;6:54.

289. Strijbos JH, Postma DS, van Altena R, Gimeno F, Koëter GH. A comparison between an outpatient hospital-based pulmonary rehabilitation program and a home-care pulmonary rehabilitation program in patients with COPD. A follow-up of 18 months. Chest 1996;109:366-72.

290. Ketelaars CA, Abu-Saad HH, Schlösser MA, Mostert R, Wouters EF. Long-term outcome of pulmonary rehabilitation in patients with COPD. Chest 1997;112:363-9.

291. Engström CP, Persson LO, Larsson S, Sullivan M. Long-term effects of a pulmonary rehabilitation programme in outpatients with chronic obstructive pulmonary disease: A randomized controlled study. Scand J Rehabil Med 1999;31:207-13.

292. Foglio K, Bianchi L, Bruletti G, Battista L, Pagani M, Ambrosino N. Long-term effectiveness of pulmonary rehabilitation in patients with chronic airway obstruction. Eur Respir J 1999;13:125-32.

293. Brooks D, Sottana R, Bell B, et al. Characterization of pulmonary rehabilitation programs in Canada in 2005. Can Respir J 2007; 14:87-92.

294. Maltais F, Bourbeau J, Lacasse Y, et al. A Canadian, multicentre, randomized clinical trial of home-based pulmonary rehabilitation in chronic obstructive pulmonary disease: Rationale and methods. Can Respir J 2005;12:193-8.

295. Goldstein RS, Gort EH, Guyatt GH, Feeny D. Economic analysis of respiratory rehabilitation. Chest 1997;112:370-9.

296. Griffiths TL, Phillips CJ, Davies S, Burr ML, Campbell IA. Cost effectiveness of an outpatient multidisciplinary pulmonary rehabilitation programme. Thorax 2001;56:779-84.

297. Long term domiciliary oxygen therapy in chronic hypoxic cor pulmonale complicating chronic bronchitis and emphysema. Report of the Medical Research Council Working Party. Lancet 1981;1:681-6.

298. Continuous or nocturnal oxygen therapy in hypoxemic chronic obstructive lung disease: A clinical trial. Nocturnal Oxygen Therapy Trial Group. Ann Intern Med 1980;93:391-8

299. Fletcher EC, Luckett RA, Goodnight-White S, Miller CC, Qian W, Costarangos-Galarza C. A double-blind trial of nocturnal supplemental oxygen for sleep desaturation in patients with chronic obstructive pulmonary disease and a daytime $\mathrm{PaO}_{2}$ above 60 mm Hg. Am Rev Respir Dis 1992;145:1070-6.

300. Chaouat A, Weitzenblum E, Kessler R, et al. A randomized trial of nocturnal oxygen therapy in chronic obstructive pulmonary disease patients. Eur Respir J 1999;14:1002-8.

301. Cormick W, Olson LG, Hensley MJ, Saunders NA. Nocturnal hypoxaemia and quality of sleep in patients with chronic obstructive lung disease. Thorax 1986;41:846-54.

302. Cranston JM, Crocket AJ, Moss JR, Alpers JH. Domiciliary oxygen for chronic obstructive pulmonary disease (Cochrane Review). In: The Cochrane Library, Issue 4, 2005. Chichester, UK: John Wiley $\&$ Sons, Ltd.

303. Fleetham J, West P, Mezon B, Conway W, Roth T, Kryger M. Sleep, arousals, and oxygen desaturation in chronic obstructive pulmonary 
disease. The effect of oxygen therapy. Am Rev Respir Dis 1982;126:429-33.

304. McKeon JL, Murree-Allen K, Saunders NA. Supplemental oxygen and quality of sleep in patients with chronic obstructive lung disease. Thorax 1989;44:184-8.

305. Bye PT, Esau SA, Levy RD, et al. Ventilatory muscle function during exercise in air and oxygen in patients with chronic air-flow limitation. Am Rev Respir Dis 1985;132:236-40.

306. O'Donnell DE, D'Arsigny C, Webb KA. Effects of hyperoxia on ventilatory limitation during exercise in advanced chronic obstructive pulmonary disease. Am J Respir Crit Care Med 2001;163:892-8.

307. O'Donnell DE, Bain DJ, Webb KA. Factors contributing to relief of exertional breathlessness during hyperoxia in chronic airflow limitation. Am J Respir Crit Care Med 1997; 155:530-5.

308. Peters MM, Webb KA, O'Donnell DE. Combined physiological effects of bronchodilators and hyperoxia on exertional dyspnoea in normoxic COPD. Thorax 2006;61:559-67.

309. Palange P, Valli G, Onorati P, et al. Effect of heliox on lung dynamic hyperinflation, dyspnea, and exercise endurance capacity in COPD patients. J Appl Physiol 2004:97:1637-42.

310. Cukier A, Ferreira CA, Stelmach R, Ribeiro M, Cortopassi F, Calverley PM. The effect of bronchodilators and oxygen alone and in combination on self-paced exercise performance in stable COPD. Respir Med 2007;101:746-53.

311. Eves ND, Petersen SR, Haykowsky MJ, Wong EY, Jones RL. Helium-hyperoxia, exercise, and respiratory mechanics in chronic obstructive pulmonary disease. Am J Respir Crit Care Med 2006; 174:763-71.

312. McDonald CF, Blyth CM, Lazarus MD, Marschner I, Barter CE. Exertional oxygen of limited benefit in patients with chronic obstructive pulmonary disease and mild hypoxemia. Am J Respir Crit Care Med 1995;152:1616-9.

313. Eaton T, Garrett JE, Young P, et al. Ambulatory oxygen improves quality of life of COPD patients: a randomised controlled study. Eur Respir J 2002;20:306-12.

314. Nonoyama ML, Brooks D, Guyatt GH, Goldstein RS. Effect of oxygen on health quality of life in COPD patients with transient exertional hypoxemia. Am J Respir Crit Care Med 2007.

315. Vergeret J, Brambilla C, Mounier L. Portable oxygen therapy: Use and benefit in hypoxaemic COPD patients on long-term oxygen therapy. Eur Respir J 1989;2:20-5.

316. Lacasse Y, Lecours R, Pelletier C, Bégin R, Maltais F. Randomised trial of ambulatory oxygen in oxygen-dependent COPD. Eur Respir J 2005;25:1032-8.

317. Bott J, Carroll MP, Conway JH, et al. Randomised controlled trial of nasal ventilation in acute ventilatory failure due to chronic obstructive airways disease. Lancet 1993;341:1555-7.

318. Brochard L, Mancebo J, Wysocki M, et al. Noninvasive ventilation for acute exacerbations of chronic obstructive pulmonary disease. N Engl J Med 1995;333:817-22.

319. Kramer N, Meyer TJ, Meharg J, Cece RD, Hill NS. Randomized, prospective trial of noninvasive positive pressure ventilation in acute respiratory failure. Am J Respir Crit Care Med 1995;151:1799-806.

320. Angus RM, Ahmed MM, Fenwick LJ, Peacock AJ. Comparison of the acute effects on gas exchange of nasal ventilation and doxapram in exacerbations of chronic obstructive pulmonary disease. Thorax 1996;51:1048-50.

321. Barbé F, Togores B, Rubí M, Pons S, Maimó A, Agustí AG. Noninvasive ventilatory support does not facilitate recovery from acute respiratory failure in chronic obstructive pulmonary disease. Eur Respir J 1996;9:1240-5.

322. Celikel T, Sungur M, Ceyhan B, Karakurt S. Comparison of noninvasive positive pressure ventilation with standard medical therapy in hypercapnic acute respiratory failure. Chest 1998;114:1636-42.

323. Avdeev SN, Tret'iakov AV, Grigor'iants RA, Kutsenko MA, Chuchalin AG. Study of the use of noninvasive ventilation of the lungs in acute respiratory insufficiency due to exacerbation of chronic obstructive pulmonary disease. Anesteziol Reanimatol 1998;45-51.

324. Confalonieri M, Potena A, Carbone G, Porta RD, Tolley EA, Umberto Meduri G. Acute respiratory failure in patients with severe community-acquired pneumonia. A prospective randomized evaluation of noninvasive ventilation. Am Respir Crit Care Med 1999; 160:1585-91.

325. Martin TJ, Hovis JD, Costantino JP, et al. A randomized, prospective evaluation of noninvasive ventilation for acute respiratory failure. Am J Respir Crit Care Med 2000;161:807-13.

326. Plant PK, Owen JL, Elliott MW. Early use of non-invasive ventilation for acute exacerbations of chronic obstructive pulmonary disease on general respiratory wards: A multicentre randomized controlled trial. Lancet 2000;355:1931-5.

327. Wijkstra PJ, Lacasse Y, Guyatt GH, Goldstein RS. Nocturnal noninvasive positive pressure ventilation for stable chronic obstructive pulmonary disease (Cochrane Review). In: The Cochrane Library, Issue 3, 2002. Chichester, UK: John Wiley \& Sons, Ltd.

328. Plant PK, Owen JL, Elliott MW. Non-invasive ventilation in acute exacerbations of chronic obstructive pulmonary disease: Long term survival and predictors of in-hospital outcome. Thorax 2001;56:708-12.

329. Soo Hoo GW, Santiago S, Williams A. Nasal mechanical ventilation for hypercapnic respiratory failure in chronic obstructive pulmonary disease: Determinants of success and failure. Crit Care Med 1994;22:1253-61.

330. Keenan SP, Powers CE, McCormack DG. Noninvasive positivepressure ventilation in patients with milder chronic obstructive pulmonary disease exacerbations: A randomized controlled trial Respir Care 2005;50:610-6.

331. Kwok H, McCormack J, Cece R, Houtchens J, Hill NS. Controlled trial of oronasal versus nasal mask ventilation in the treatment of acute respiratory failure. Crit Care Med 2003;31:468-73.

332. Levy M, Tanios MA, Nelson D, et al . Outcomes of patients with do-not-intubate orders treated with noninvasive ventilation. Crit Care Med 2004;32:2002-7.

333. Schettino G, Altobelli N, Kacmarek RM. Noninvasive positive pressure ventilation reverses acute respiratory failure in select "do-not-intubate" patients. Crit Care Med 2005;33:1976-82.

334. Benhamou D, Girault C, Faure C, Portier F, Muir JF. Nasal mask ventilation in acute respiratory failure. Experience in elderly patients. Chest 1992;102:912-7.

335. Chu CM, Chan VL, Wong IW, Leung WS, Lin AW, Cheung KF. Noninvasive ventilation in patients with acute hypercapnic exacerbation of chronic obstructive pulmonary disease who refused endotracheal intubation. Crit Care Med 2004:32:372-7.

336. Criner GJ, Cordova SC, Furukawa S, et al. Prospective randomized trial comparing bilateral lung volume reduction surgery to pulmonary rehabilitation in severe chronic obstructive pulmonary disease. Am J Respir Crit Care Med 1999;160:2018-27.

337. Goodnight-White S, Jones WJ, Baaklini WA, et al. Prospective randomized controlled trial comparing bilateral lung volume reduction surgery (LVRS) to medical therapy alone in patients with severe emphysema. Chest 2000;118(Suppl 4):102S.

338. Hillerdal G, Löfdahl CG, Ström K, et al. Comparison of lung volume reduction surgery and physical training on health status and physiologic outcomes: A randomized controlled clinical trial. Chest 2005;128:3489-99

339. Geddes D, Davies M, Koyama H, et al. Effect of lung-volumereduction surgery in patients with severe emphysema. N Engl J Med 2000;343:239-45.

340. Pompeo E, Marino M, Nofroni I, Matteucci G, Mineo TC. Reduction pneumoplasty versus respiratory rehabilitation in severe emphysema: A randomized study. Pulmonary Emphysema Research Group. Ann Thorac Surg 2000;70:948-53.

341. Goldstein RS, Todd TR, Guyatt G, et al. Influence of lung volume reduction surgery (LVRS) on health related quality of life in patients with chronic obstructive pulmonary disease. Thorax 2003;58:405-10.

342. Fishman A, Martinez F, Naunheim K, et al. A randomized trial comparing lung-volume-reduction surgery with medical therapy for severe emphysema. N Eng J Med 2003;348:2059-73.

343. Miller JD, Berger RL, Malthaner RA, et al. Lung volume reduction surgery versus medical treatment: For patients with advanced emphysema. Chest 2005;127:1166-77.

344. Miller JD, Malthaner RA, Goldsmith CH, et al. A randomized clinical trial of lung volume reduction surgery versus best medical care for patients with advanced emphysema: A two-year study from Canada. Ann Thorac Surg 2006;81:314-20. 
345. National Emphysema Treatment Trial Research Group. Patients at high risk of death after lung-volume-reduction surgery. $\mathrm{N}$ Engl J Med 2001;345:1075-83.

346. Naunheim KS, Wood DE, Mohsenifar Z, et al. Long-term follow-up of patients receiving lung-volume-reduction surgery versus medical therapy for severe emphysema by the National Emphysema Treatment Trial Research Group. Ann Thorac Surg 2006;82:431-43.

347. Ramsey SD, Berry K, Etzioni R, et al. Cost effectiveness of lungvolume-reduction surgery for patients with severe emphysema. N Engl J Med 2003;348:2092-102.

348. Hopkinson NS, Toma TP, Hansell DM et al. Effect of bronchoscopic lung volume reduction on dynamic hyperinflation and exercise in emphysema. Am J Respir Crit Care Med 2005;171:453-60.

349. Hosenpud JD, Bennett LE, Keck BM, Boucek MM, Novick RJ. The Registry of the International Society for Heart and Lung Transplantation: Eighteenth official report - 2001. J Heart Lung Transplant 2001;20:805-15.

350. Arcasoy SM, Kotloff RM. Lung transplantation. N Engl J Med 1999;340:1081-91.

351. Orens JB, Estenne M, Arcasoy S, et al. International guidelines for the selection of lung transplant candidates: 2006 update a consensus report for the Pulmonary Scientific Council of the International Society for Heart and Lung Transplantation. J Heart Lung Transplant 2006;25:745-55.

352. Abboud RT, Ford GT, Chapman KR, Standards Committee of the

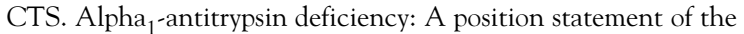
Canadian Thoracic Society. Can Respir J 2001;8:81-8.

353. Abboud RT, Ford GT, Chapman KR. Emphysema in alpha - $^{-}$ antitrypsin deficiency: Does replacement therapy affect outcome? Treat Respir Med 2005;4:1-8.

354. McNeely PD, Hébert PC, Dales RE, et al. Deciding about mechanical ventilation in end-stage chronic obstructive pulmonary disease: How respirologists perceive their role. CMAJ 1997;156:177-83.

355. Hansen-Flaschen J. Chronic obstructive pulmonary disease: The last year of life. Respir Care 2004:49:90-7.
356. Soler-Cataluna JJ, Martinez-Garcia MA, Roman Sanchez P, et al. Severe acute exacerbations and mortality in patients with chronic obstructive pulmonary disease. Thorax 2005;60:925-31.

357. Lynn J, Ely EW, Zhong Z, et al. Living and dying with chronic obstructive pulmonary disease. J Am Geriatr Soc 2000;48(Suppl 5):91S-100S.

358. Gore JM, Brophy CJ, Greenstone MA. How well do we care for patients with end stage chronic obstructive pulmonary disease (COPD)? A comparison of palliative care and quality of life in COPD and lung cancer. Thorax 2000;55:1000-6.

359. van Ede L, Yzermans CJ, Brouwer HJ. Prevalence of depression in patients with chronic obstructive pulmonary disease: A systematic review. Thorax 1999;54:688-92.

360. Lacasse Y, Rousseau L, Maltais F. Prevalence of depressive symptoms and depression in patients with severe oxygen-dependent chronic obstructive pulmonary disease. J Cardiopulm Rehabil 2001;21:80-6.

361. Heyland DK, Dodek P, Rocker G, et al. What matters most in endof-life care: perceptions of seriously ill patients and their family members. CMAJ 2006;174:627-33.

362. Hurt RD, Sachs DP, Glover ED, et al. A comparison of sustainedrelease bupropion and placebo for smoking cessation. N Engl J Med 1997;337:1195-202.

363. Jorenby DE, Leischow SJ, Nides MA, et al. A controlled trial of sustained-release bupropion, a nicotine patch, or both for smoking cessation. N Engl J Med 1999;340:685-91.

364. Important Safety Information Regarding Bupropion. Letter sent to Canadian Health Professionals 3 July 2001. Ravinder Kumar PhD, Vice President, regulatory affairs and pharmaceutical development, GlaxoSmithKline Inc.

365. Revision to the monograph of Zyban (bupropion hydrochloride). Letter sent to Canadian Health Professionals June 2002. Joy DasGupta BSc Pharm, Chief of Therapeutic Field, metabolism/cardiovascular/infectious disease. Medical service, GlaxoSmithKline Inc.

366. Product Monograph: Champix (varenicline tartrate tablets). 2007. 


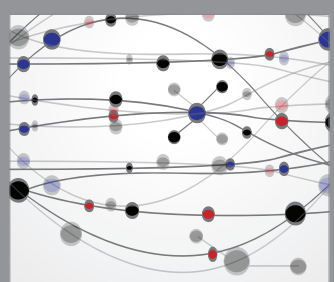

The Scientific World Journal
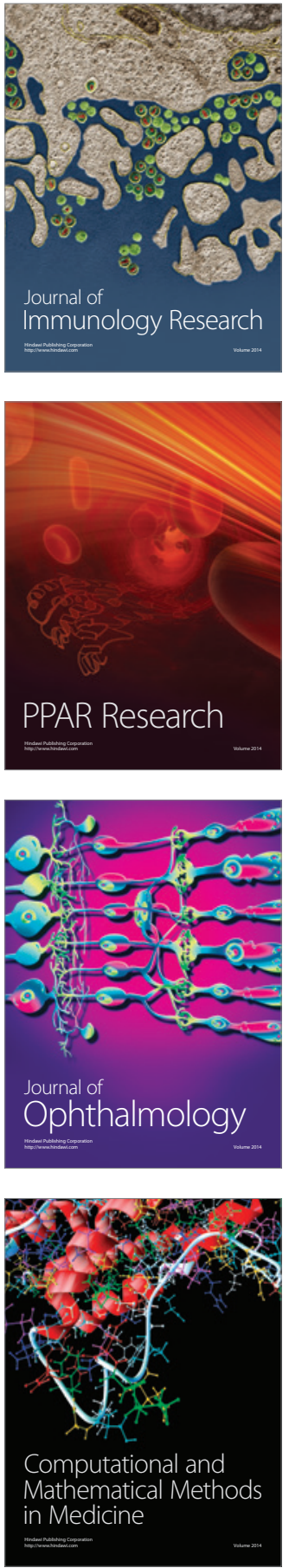

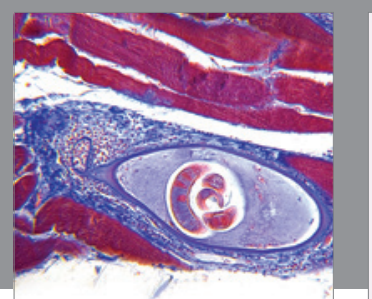

Gastroenterology Research and Practice

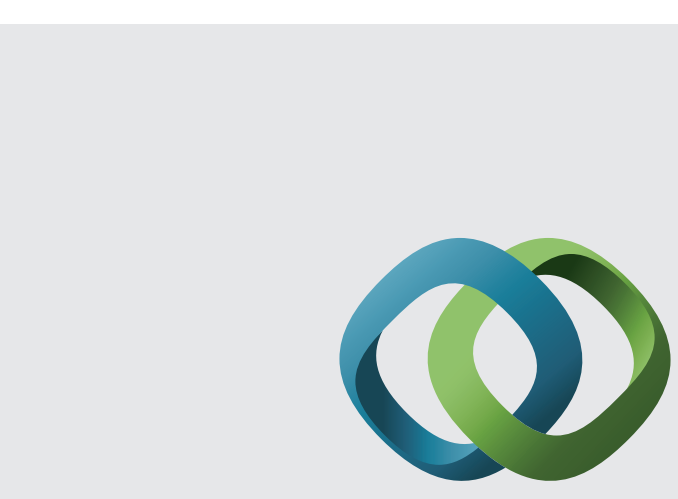

\section{Hindawi}

Submit your manuscripts at

http://www.hindawi.com
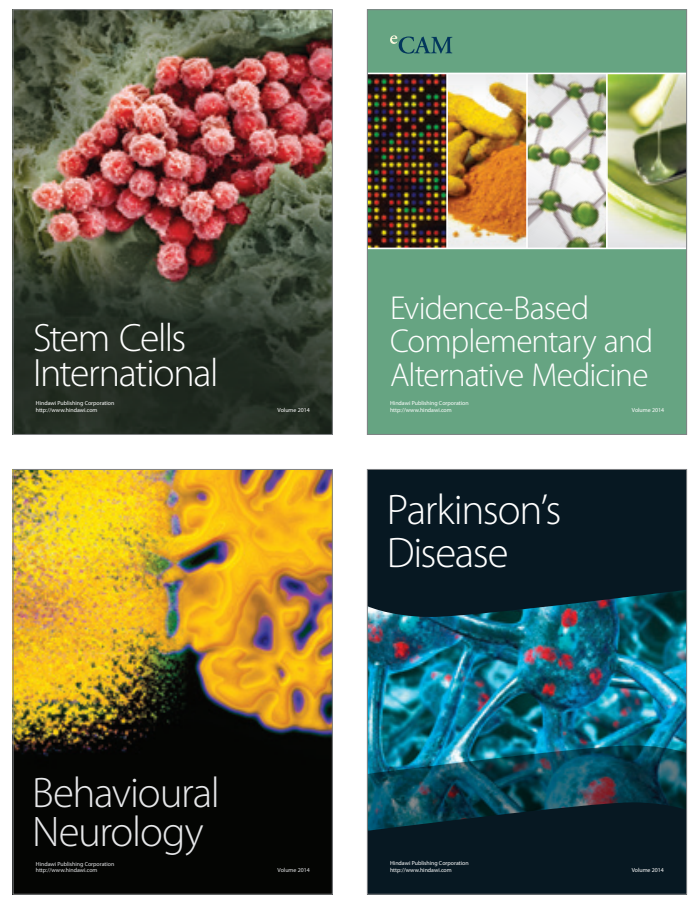
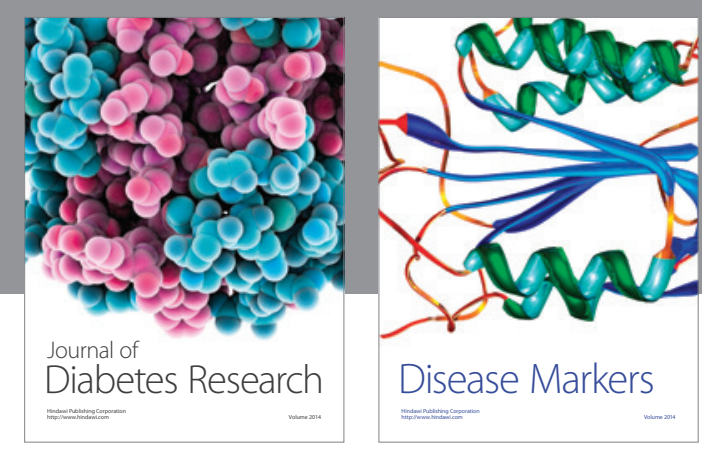

Disease Markers
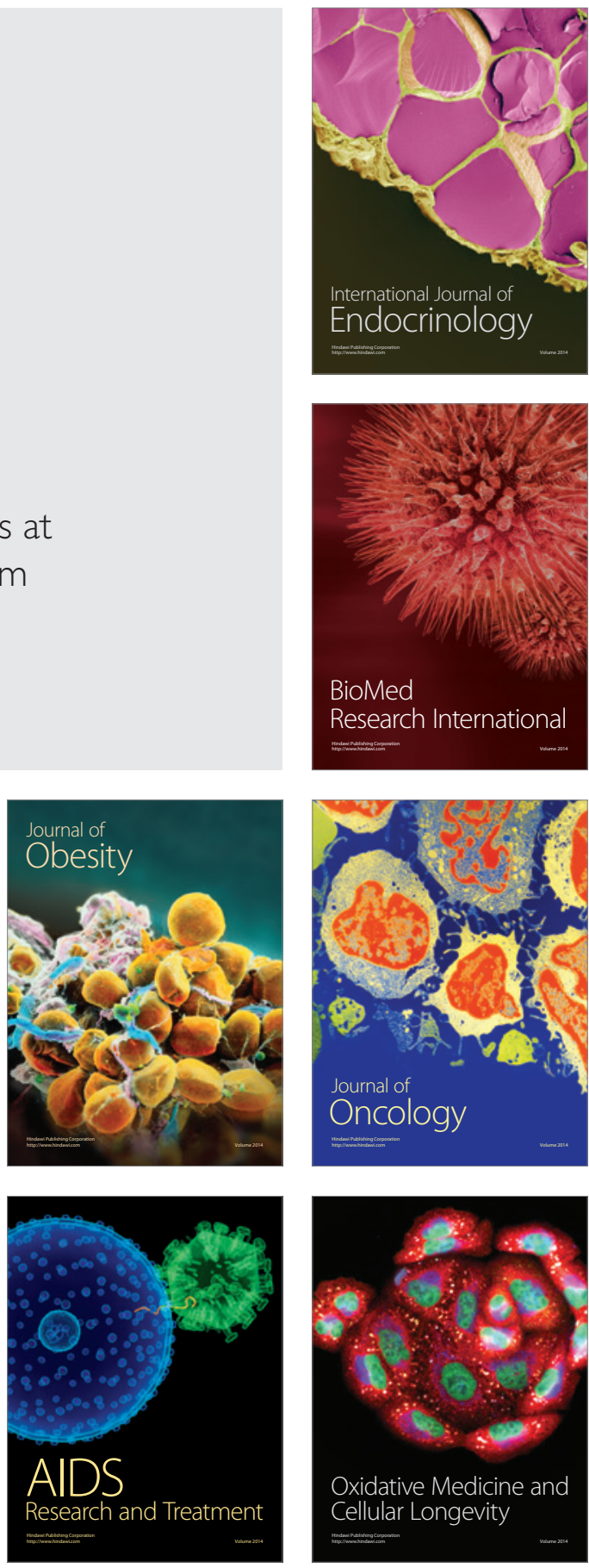